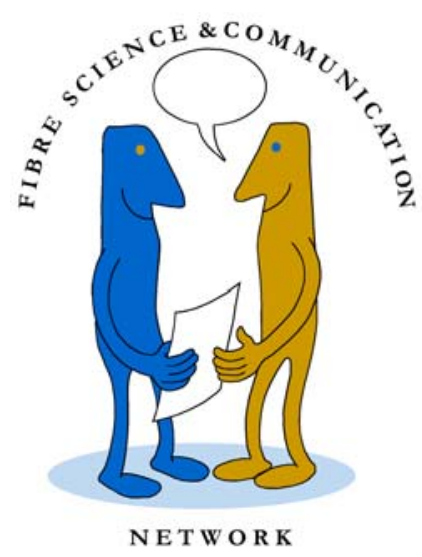

\title{
Spreading of droplets of different liquids on specially structured papers
}

Lars Wågberg, Mitthögskolan

Christina Westerlind, SCA Graphic Research

\section{Report number: R-00-3}

August 2000

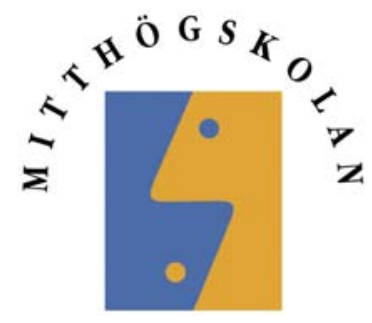

Mid Sweden University

Fibre Science and Communication Network

SE-851 70 Sundsvall, Sweden

Internet: http://www.mh.se/fsen 

$\begin{array}{ll}\text { Background } & 5\end{array}$

Experimental $\quad 6$

$\begin{array}{ll}\text { Part one - Production of model papers } & 6\end{array}$

$\begin{array}{ll}\text { Part two - Production of model papers } & 7\end{array}$

$\begin{array}{ll}\text { The instrumental method } & 7\end{array}$

Results and discussion $\quad 8$

Spreading of liquid drops on hydrophilic papers with different structures $\quad 8$

Spreading of liquid drops on papers with different degrees of

hydrphobicity and with different types of imprinted structures 16

$\begin{array}{ll}\text { Summary } & 26\end{array}$

$\begin{array}{ll}\text { References } & 27\end{array}$

\begin{tabular}{lll}
\hline Distribution list & & \\
FSCN Ledningsgrupp & $(12)$ & Hans Pettersson, SCA Graphic Ortviken \\
Referensgrupp Teknisk Fiberkemi & $(16)$ & Inger Eriksson, SCA Graphic Ortviken \\
Referensgrupp Mek. Fiberteknologi & $(13)$ & Folke Österberg, SCA Packaging Res.
\end{tabular}




\title{
Spreading of droplets of different liquids on specially structured papers
}

\author{
Lars Wågberg* and Christina Westerlind** \\ * Mid-Sweden University, Dept.Chemistry and Process Technology, 85170 Sundsvall, Sweden \\ ** SCA Graphic Research, Box 3054, 85003 Sundsvall, Sweden
}

\begin{abstract}
The spreading of drops of different liquids (water, glycerol and ethylene glycol) on different types of model papers has been investigated by using a system based on image analysis of drop spreading on paper. In the first part of the investigation two different types of papers were investigated: homogenous sheets and two ply sheets. The two ply sheets consisted of an upper layer made from fibres with a low degree of beating and a lower layer that varied in the degree of beating. The homogeneous sheets were made from fibres with different degrees of beating. The results from this first part show that
\end{abstract}

a) The initial spreading of the different liquids on the papers is to a large extent controlled by the hydrodynamic properties of the liquids.

b) The bulk structure of the sheets has a large influence on the balance between absorption and spreading of droplets on/into the paper. For unbeaten pulps there is an immediate absorption of the liquid but for the more highly beaten pulps the absorption can be neglected during the first seconds of the spreading. This also means that it is hard to determine a contact angle between the paper and the liquid for the unbeaten pulps whereas it is possible for the denser sheets.

c) For the two-ply sheets the spreading/absorption is almost entirely controlled by the properties of the top ply.

It is also proposed that in order to determine a contact angle on the paper the volume of the drop on the paper should be constant and the contact angle should be determined at the time when the drop has just reached its equilibrium spreading radius.

In the second part of the investigation different surface structures of the papers were constructed by pressing the papers against wires of different coarseness and in this part the influence of sizing of the papers was also investigated. A detailed characterisation of the surface structure was also conducted. The results from this part of the investigation show that 
a) When there is a continuous pattern on the surface, with surface capillaries, the contact angle is decreased compared with the situation with a flat surface according to the Wenzel equation. This is the situation for the papers pressed against the fine wire.

b) For the papers pressed against the coarser wire a rougher surface is created with large continuos barriers. These barriers lead to an apparent contact angle between water and paper that is higher than for the flat surface according to the equation proposed by Shuttleworth and Bailey.

c) For glycerol the influence of the surface roughness is not exactly the same except for the sheets with the largest degree of sizing where the fine capillaries on the surface decreases the detected contact angle. This in turn shows an influence of the spreading parameter on the spreading process.

A simple attempt to fit the data to a power law based on the hydrodynamic approach was also conducted. The results from this treatment show that it is possible to get a good match for sheets with virtually only surface spreading and the constants achieved in this treatment can be used to rationalise the spreading data to be compared with other investigations.

In summary this work shows that it is possible to get a good correlation between surface energy, sheet and surface structure and the properties of the liquid in question using this technique. However, the correlations are not simple and great care has to be taken to interpret wetting and absorption results correctly.

Key Words: Absorption, kinetics,liquids, models, papers,paper structure,spreading, water repellence, wetting. 


\section{Background}

A knowledge of the factors controlling the interaction between liquids and paper is essential in order to control the behaviour of paper in for example printing and coating operations. In the printing operation different types of liquids are used and furthermore different processes, responsible for the liquid/paper interaction, are active in different parts of the printing process. The situation is equivalent in the coating process but in this process only water is used as solvent. Despite these complications it is clear that knowledge of the fundamental interaction between the liquids and the paper, i.e. the wetting of the components in the paper by the different liquids, is of primary importance for paper quality optimisation (1-3).

In flexo printing as well as in offset printing there is a considerable influence of forced wetting and as was shown in (4) the spontaneous wetting properties of the paper become less important under these conditions. However, during ink setting the spontaneous wetting starts to become important and therefore the wetting properties of the paper are also important for these printing operations. In more modern printing techniques where water is used as solvent, such as ink-jet printing, the wetting properties of the paper become even more important and it has also been shown that it is necessary to manage both the structure and the surface energy of the paper in order to optimise the ink-jet print quality (5-8).

In order to determine the surface energy of the paper it is very common to use contact angle measurements with one or several liquids $(8,9)$. However, contact angle measurements on paper are always subject to discussions regarding their reliability since the papers are rough, porous and inhomogeneous. Furthermore there is also a controversy regarding the usefulness of contact angle measurements, for surface energy determinations. Despite this, contact angle measurements are frequently used, mainly due to the simplicity of use, the availability of good measuring equipment and the correlation between the measured values of the surface energy and the properties of the paper. Today there is also a good understanding of the factors which control the equilibrium contact angle on solid surfaces where both chemical inhomogeneity and surface roughness are considered (10-14).

In many practical applications the dynamic conditions are of greater importance than the static conditions. Consequently the dynamics of wetting has attracted a considerable research interest over the last ten decades (15-22) and today there are several theories available which describe the spreading of drops on different types of surfaces. The two dominating models are the 1) Hydrodynamic approach $(23,24)$ and 2) the Molecular kinetics approach (25). It is not the purpose of the present work to add to the theoretical development in this area but the hydrodynamic approach will be used in the evaluation of results in order to rationalise the data.

It is important to quantify the importance of different factors on the spreading of droplets of different liquids on different types of papers and how different factors will alter the value of the contact angle. With this as background and with the improved knowledge on the spreading of droplets on well characterised surfaces it was decided to 
study the dynamics of the spreading of liquid droplets on model papers where the surface structure, bulk structure and surface energy had been altered in a controlled way. It was also the purpose of the present work to determine if it is possible to determine the contact angle between different liquids and different papers.

\section{Experimental}

\section{Part one - Production of model papers.}

Two types of paper sheets were prepared to study the influence of bulk structure on the spreading and absorption of different liquids; two-layer sheets, $40+40 \mathrm{~g} / \mathrm{m}^{2}$, and homogenous sheets, $80 \mathrm{~g} / \mathrm{m}^{2}$ (figure 1). The sheets were prepared from a TCF pulp (hardwood) delivered in dry lap form from SCA Graphic Östrand, Sundsvall, Sweden. The pulp was beaten to different degrees in an Escher-Wyss laboratory refiner (internal SCA standard at an edge load of $0,5 \mathrm{Ws} / \mathrm{m}$ and with re-circulation of the pulp until the desired degree of beating has been achieved) before they were formed in a Dynamic sheet former (Fibertech AB, Sweden) according to standard procedures using tap water (26).

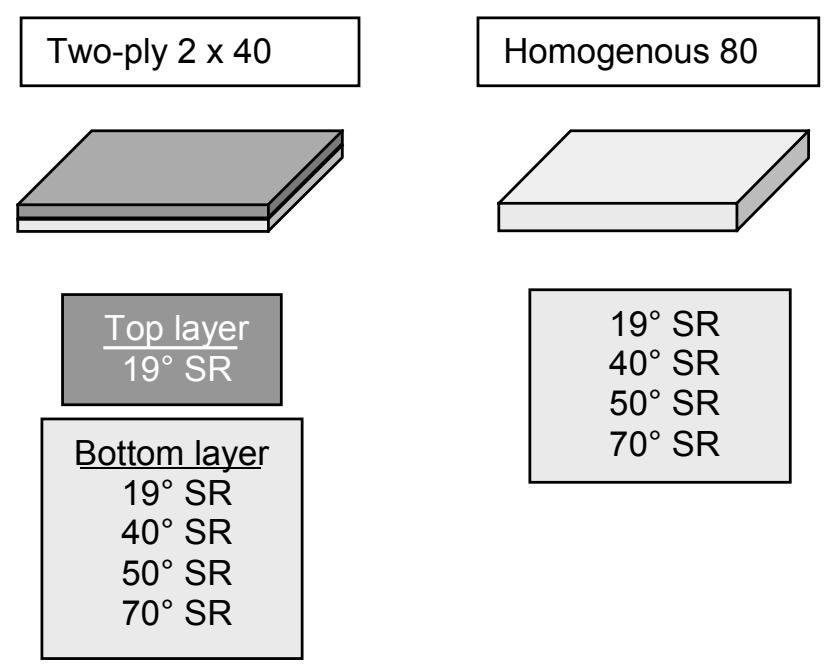

Figure 1. Composition of the two-layer and homogenous sheets used in the first part of the investigation.

Four different two-ply sheets were produced, all with a top layer made of pulp beaten to $19^{\circ} \mathrm{SR}$. By adding bottom layers made of pulps beaten to different degrees $(19,40,50$ and $70^{\circ} \mathrm{SR}$ ) a variation in bulk structure was created. The four homogenous sheets were made of pulp beaten to the same degrees as the bottom layers in the two-ply sheets. All measurements with the two-ply sheets were made with the topside contacting the droplets. 


\section{Part two - production of model papers.}

A set of laboratory sheets were produced (according to SCAN C 26:76) in order to study how the hydrophobicity and surface structure of paper influence the spreading of liquid droplets. The sheets were made of hardwood pulp beaten to $40^{\circ} \mathrm{SR}$.

Three different levels of hydrophobicity were obtained by adding different amounts of AKD to the stock; 0,2, 0,6 and 1,0 mg/g. The different surface structures were created by pressing the sheets towards either a smooth plate, a 300 mesh screen wire (stainless) or a 100 mesh screen wire (bronze) during drying (figure 2). After drying the sheets were cured at $105^{\circ} \mathrm{C}$ for ten minutes to allow sizing development. Surface profile measurement using an Optical Profile Tester (27) was used to quantify the effect of the treatment.

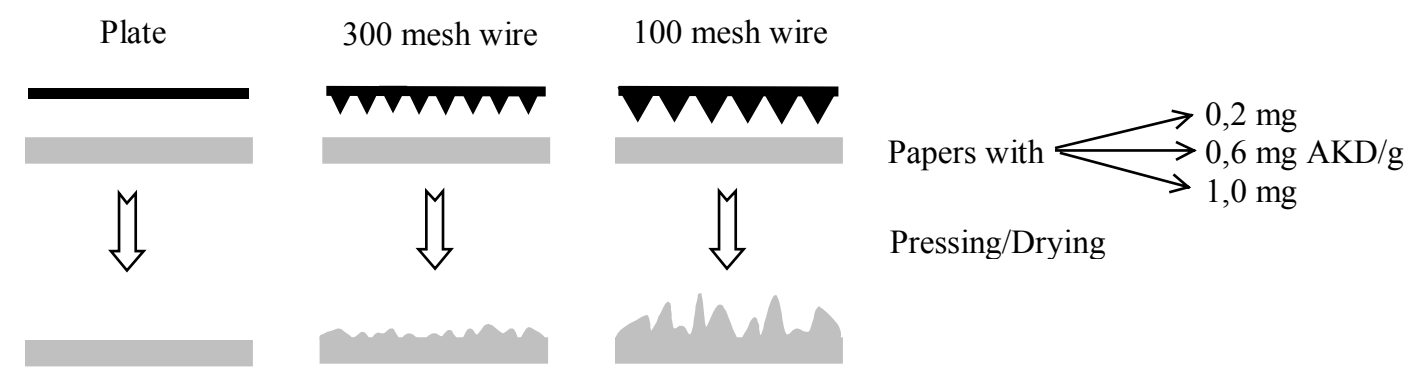

Figure 2. The forming of sheets with different extent of hydrophobicity and different surface structures used in the second part of the investigation.

\section{The instrumental method}

The measurements were performed using an Dynamic Absorption Tester, Fibro DAT 1121/1122 (Fibro System AB, Stockholm, Sweden). This equipment is capable of evaluating different kind of wettability properties with the help of image analysis.

The apparatus consists of a capillary, which is connected to a syringe with the ability to pump out accurate volumes of test fluid. The capillary is made from PTFE (polytetraflourethane) which enables a smooth transfer of the drop to the test material. The capillary is connected to a drop applicator that in the beginning of the measurement makes a slight movement to release the drop.

After drop application a computer controlled CCD-camera records the process. During the first second one picture is recorded every $20 \mathrm{~ms}$ (each picture is captured within 1 $\mathrm{ms}$ ), i.e. spreading and absorption can be studied at very short contact intervals. From one second up to a pre-set end of measurement the pictures are recorded with an interval of approx. 0.4 seconds. 
The drop captured in each image is analysed with respect to its base, height and shape, and from these values the contact angle, volume and contact area are calculated for each image. Since this kind of measurement is highly sensitive to contamination of the paper, the samples were handled using cotton gloves.

To minimise the effect of anisotropy for the papers manufactured in the dynamic sheet former all samples were cut at an angle of $45^{\circ}$ to machine direction.

The properties of the three different liquids (water, ethylene glycol and glycerol) used in the study are presented in the table 1 below.

Table 1. Properties of liquids used in the investigation.

\begin{tabular}{|l|c|c|c|}
\hline \multicolumn{1}{|c|}{ Liquid } & $\gamma_{1}$ & $\gamma_{1}$ LW & $\eta$ \\
\hline Water & 72,8 & 21,8 & 0,001 \\
\hline Ethylene glycol & 48,0 & 29,0 & 0,02 \\
\hline Glycerol & 64,0 & 34,0 & 1,49 \\
\hline
\end{tabular}

$\gamma=\mathrm{mJ} \mathrm{m}^{-2} \quad \eta=\mathrm{Ns} / \mathrm{m}^{2}$

All liquids were of analytical grade and were supplied by Kebo AB, Stockholm, Sweden. They were used as received without further purification.

\section{Results and discussion}

\section{Spreading of liquid drops on hydrophilic papers with different structures}

In the first part of this investigation the spreading of water, ethylene glycol and glycerol droplets on different model papers was investigated. The papers were either two-layered with the same type of fibres, i.e. degree of beating, in the top layer or homogeneous where the same type of fibres were used for the entire sheet. The results for the twolayered sheets are shown in figure 3 (a-c) and for the homogeneous sheets the results are shown in figure 4 (a-c). There is a large change in the contact angle with time. 


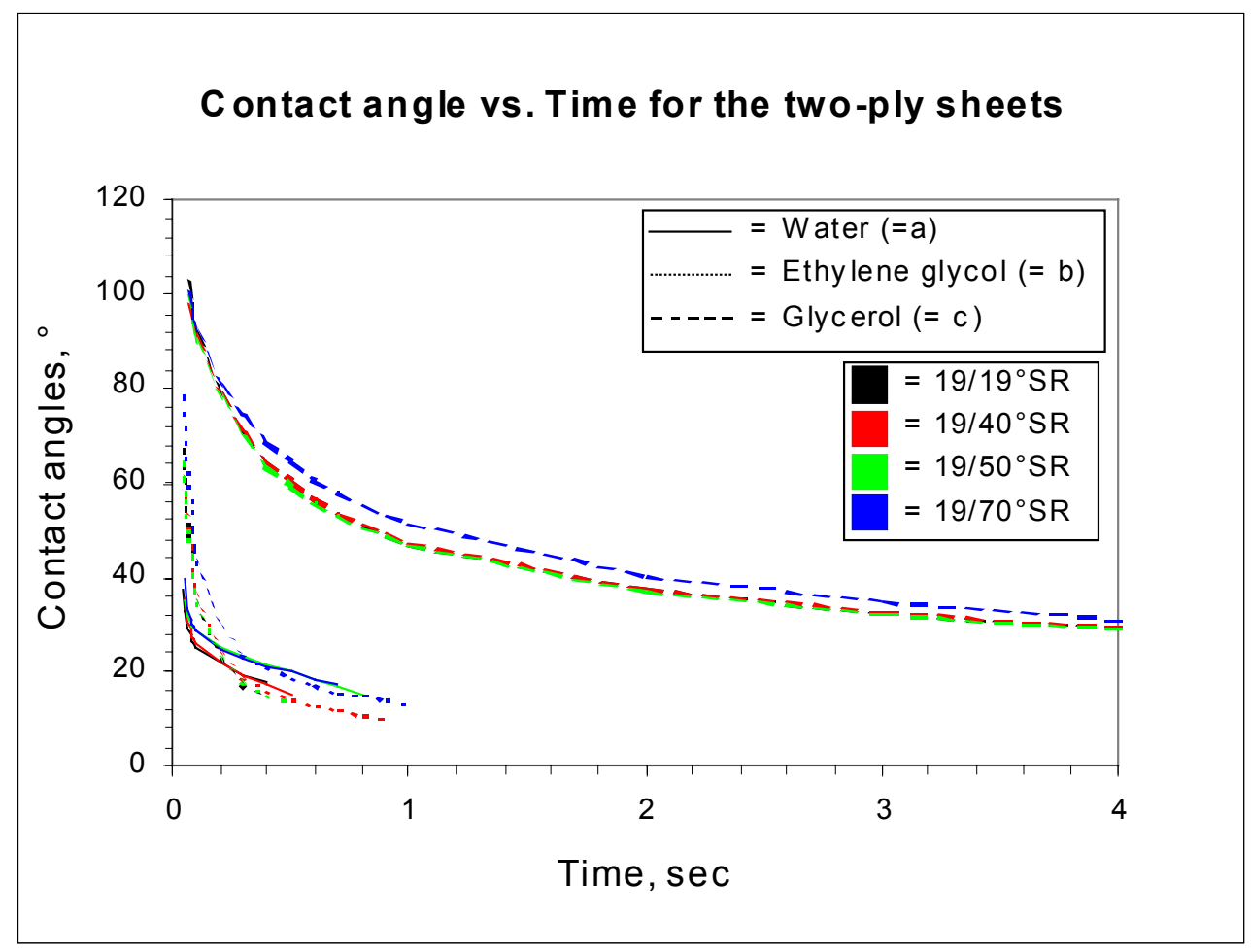

Figure 3 a-c. Change of contact angle for water (a), ethylene glycol (b) and glycerol (c) droplets on two-ply sheets where the top ply always has the lowest degree of beating, 19 SR.

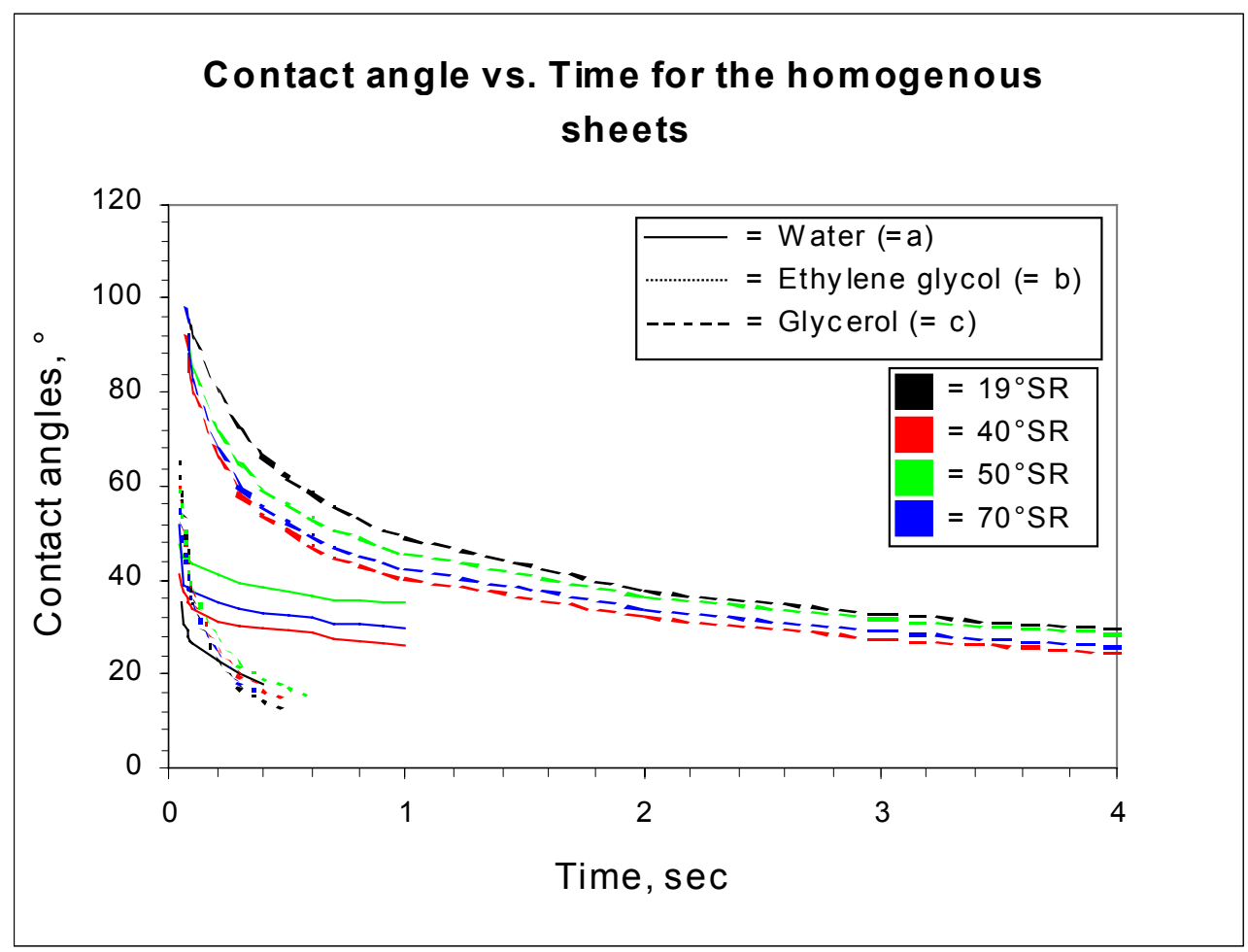

Figure 4 a-c. Change of contact angle for water (a), ethylene glycol (b) and glycerol (c) droplets on homogeneous sheets. The degree of beating is shown in the figure. 
There are possibly several reasons for this change in contact angle and the most obvious are the following.

1) Difference between the initial contact angle and the equilibrium angle

2) Penetration of the liquid into the paper giving an apparent change of the contact angle which has not necessarily something to do with approach to a final equilibrium contact angle.

3) Change in spreading mode from the initial contact between the drop and the paper and the situation when the drop has been in contact with the paper for a time long enough to allow the liquid to create a vapour phase in front of the drop.

In order to clarify the reason behind these different processes the change of the drop radius and drop volume with time was plotted as a function of time and these results are shown in figures 5 (a-c) and 6 (a-c).

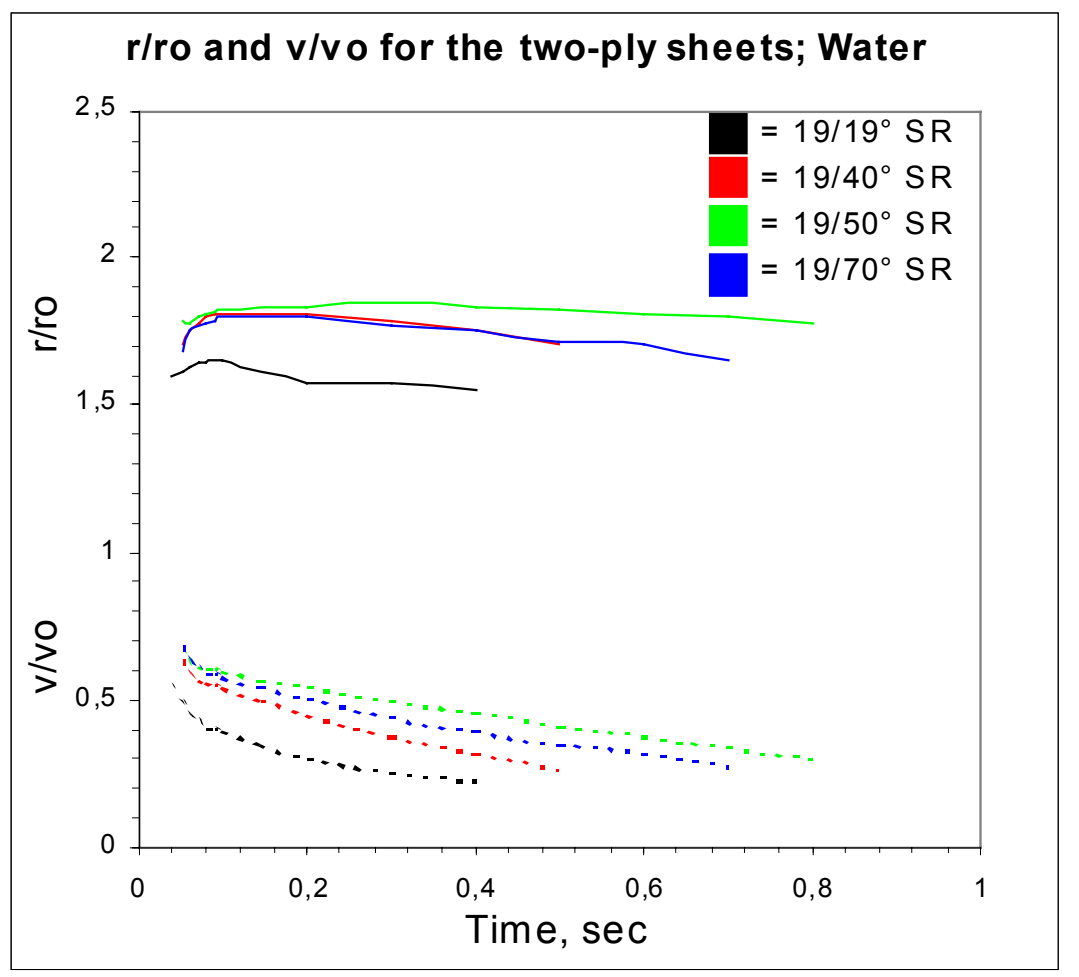

Figure 5a. $\quad r / r_{0}$ and $V / V_{0}$ for water droplets as a function of time for the two ply sheets where the top ply always has the lowest degree of beating , 19 SR 


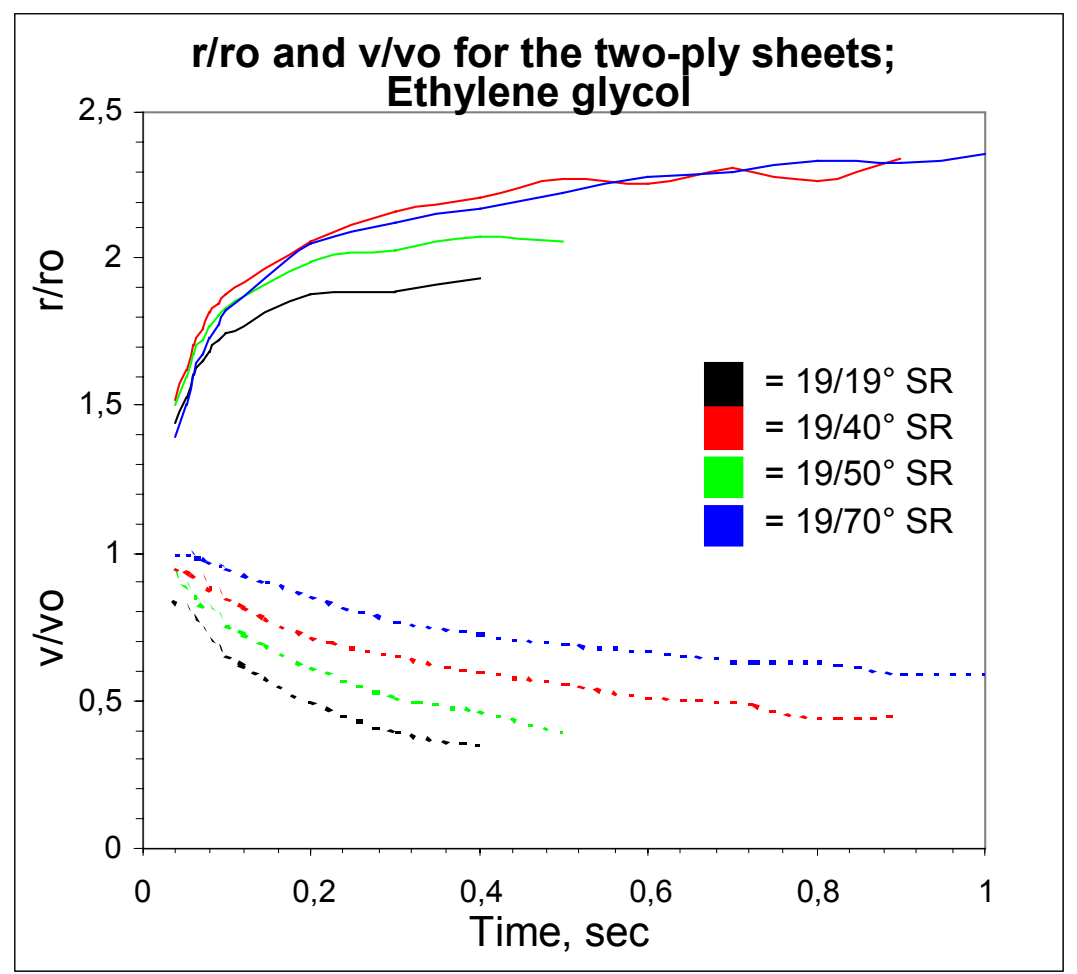

Figure 5b. $\quad r / r_{0}$ and $V / V_{0}$ for ethylene glycol droplets as a function of time for the two ply sheets where the top ply always has the lowest degree of beating , 19 SR

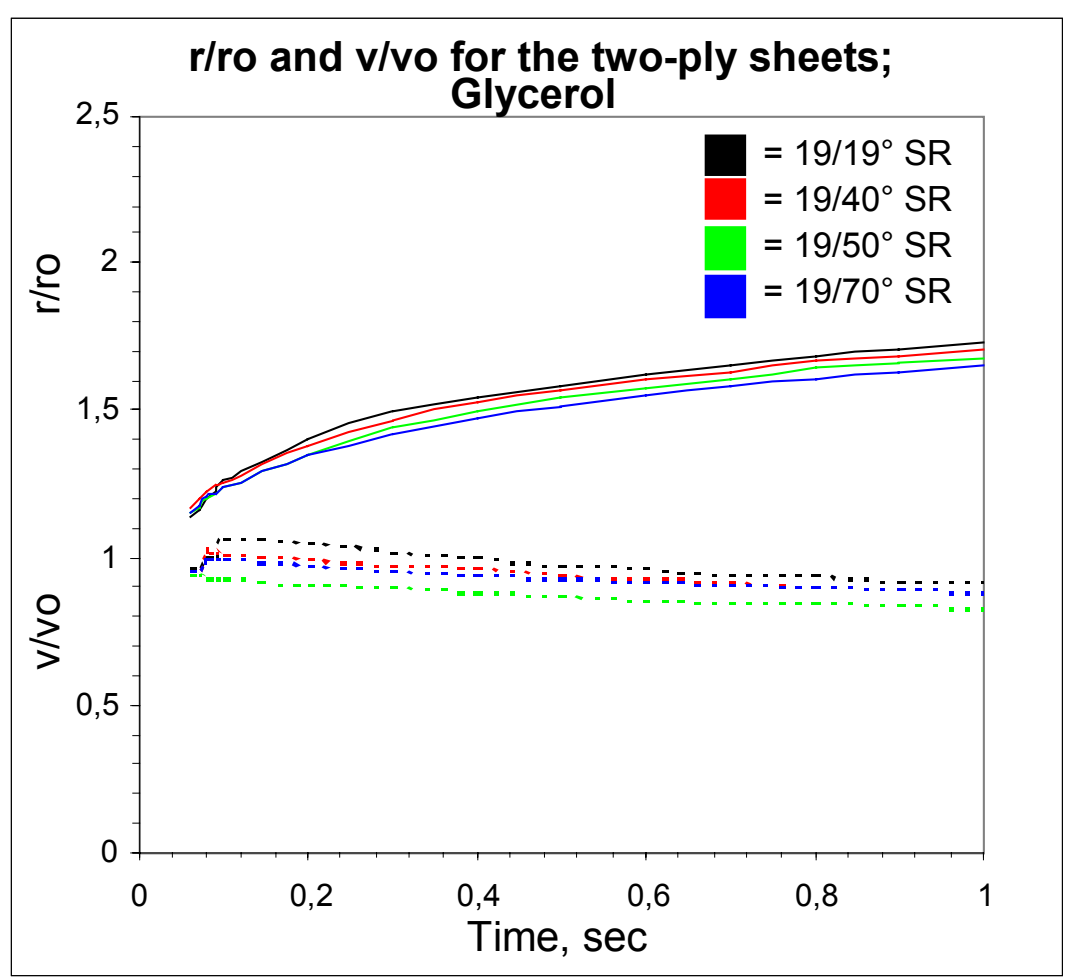

Figure 5c. $\quad r / r_{0}$ and $V / V_{0}$ for glycerol droplets as a function of time for the two ply sheets where the top ply always has the lowest degree of beating , 19 SR 


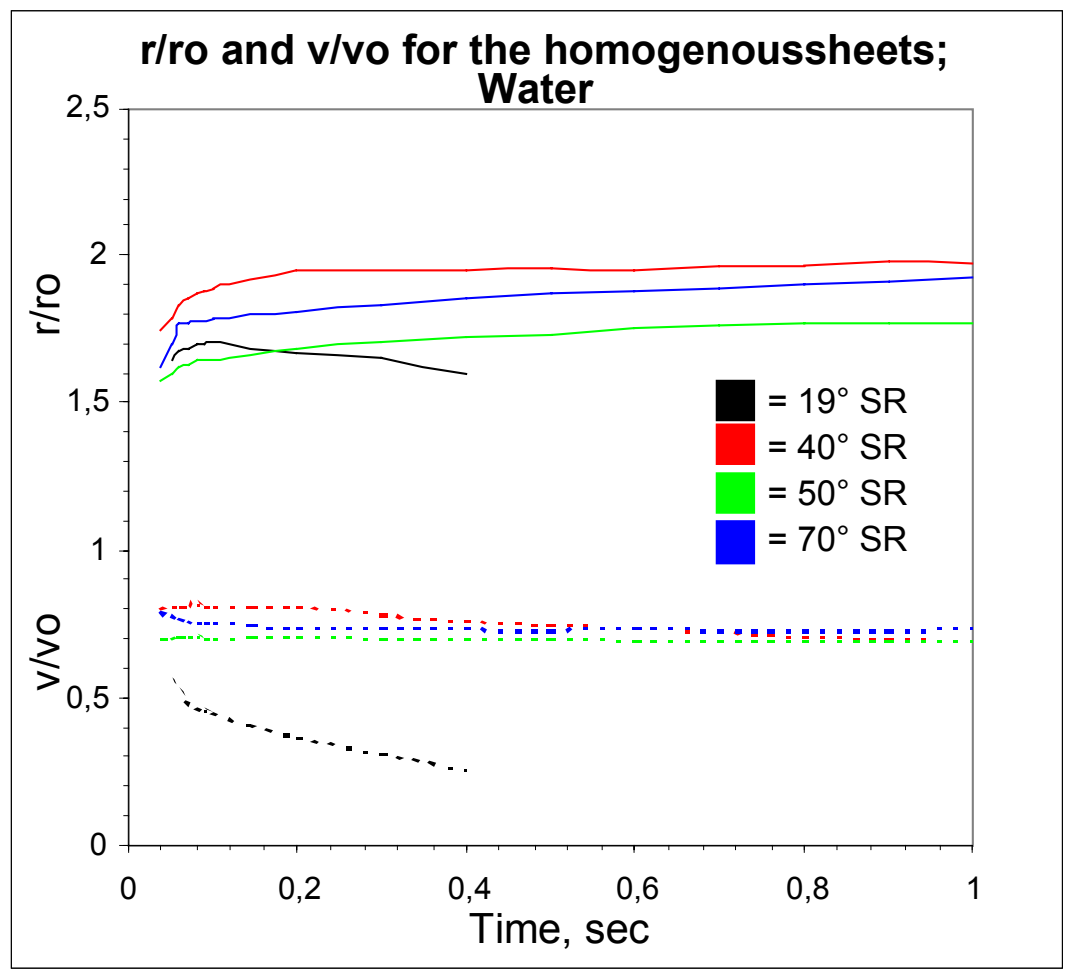

Figure 6a. $\quad r / r_{0}$ and $V / V_{0}$ for water droplets as a function of time for the homogeneous sheets. The degree of beating is shown in the figure.

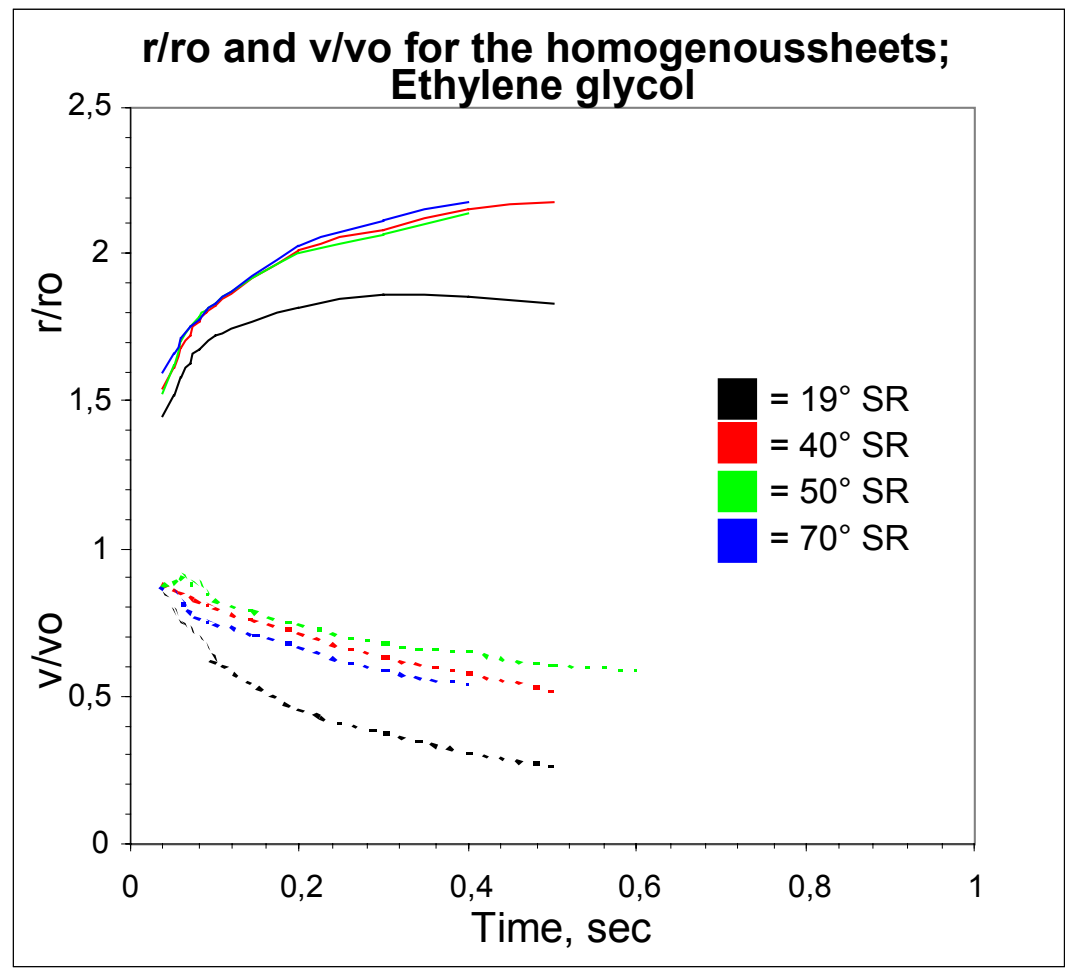

Figure 6b. $\quad r / r_{0}$ and $V / V_{0}$ for ethylene glycol droplets as a function of time for the homogeneous sheets. The degree of beating is shown in the figure. 


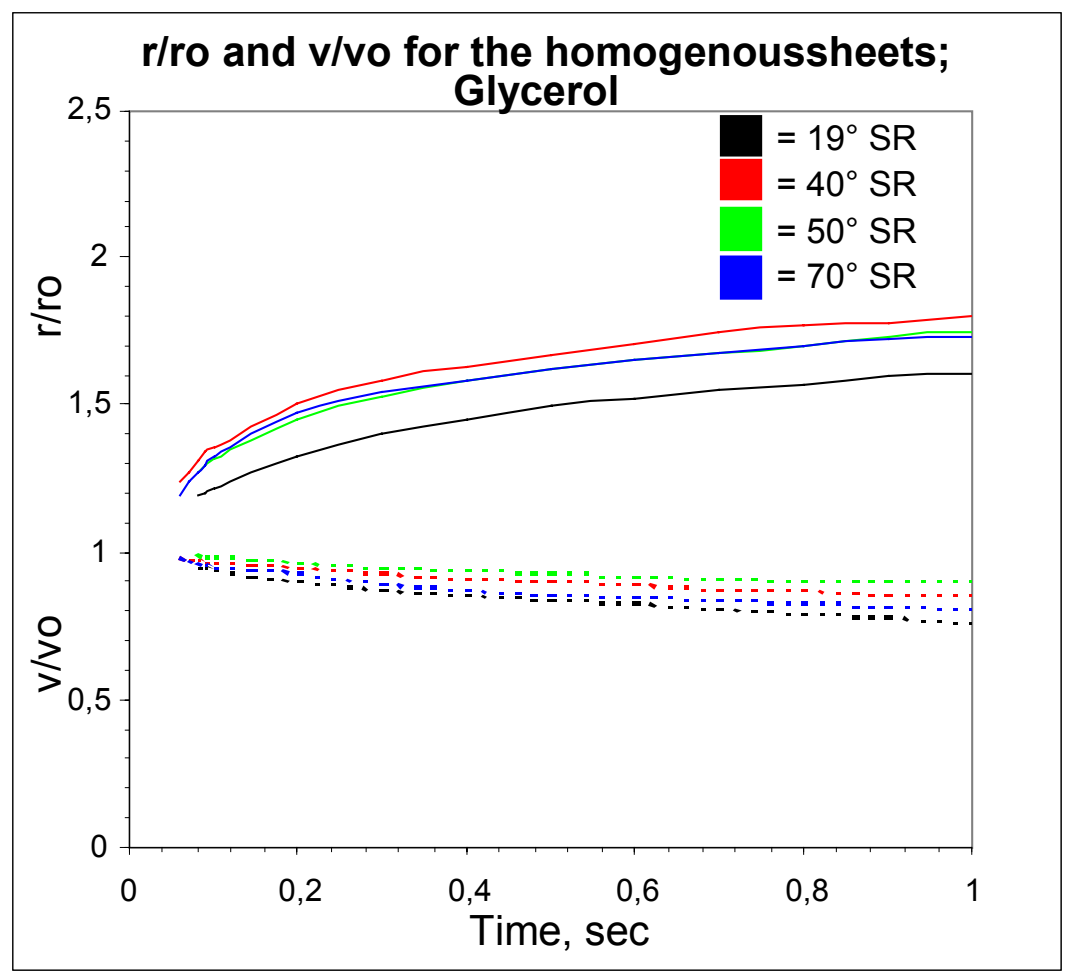

Figure 6c. $\quad r / r_{0}$ and $V / V_{0}$ for glycerol droplets as a function of time for the homogeneous sheets. The degree of beating is shown in the figure.

The results of the spreading of water droplets on the two ply papers show that there is always penetration of the water droplet into the papers regardless of the structure of the second ply. This process can be described by the methodology developed by Marmur (28) and this effect is a combination of spreading and penetration and shows that the contact angles detected with the present equipment probably are not related to the true contact angle of water on the fibres constituting the paper. For the sheets with a bottom ply of lowest porosity a small effect can be detected and this can most probably be ascribed to a decreased local volume for the drop penetrating the two layers. Since the available volume is decreased a decrease in absorption rate, i.e change of $\mathrm{V} / \mathrm{V}_{0}$, can be expected.

For the homogeneous sheets the spreading of the water droplets look quite different. For the sheet made from fibres with a degree of beating of 19 SR the situation is naturally the same as for the two-ply sheets. However, for the sheets made from fibres with a higher degree of beating the volume is constant and the $r / r_{0}$ reaches a constant value after about 1,0 $\mathrm{s}$ which indicates that the drop has reached a final equilibrium after this time. It is suggested that the contact angle at the moment when the drop has reached its equilibrium level is accepted as a measure of the contact angle of the liquid on the fibre material. This is valid only if there is no absorption (or a negligible amount) of the water droplets into the sheet. The contact angle achieved in this way is also within the limits as summarised by Wågberg and Annergren (9) for similar types of fibres. 
In figure $4 \mathrm{a}$ it can also be shown that there is a difference in contact angle for the highest degrees of beating and there is a decrease in the contact angle despite no difference in $\mathrm{V} / \mathrm{V}_{0}$ with time. The data in figure $6 \mathrm{a}$ shows that as the beating is increased from 50 to $70 \mathrm{SR}$ there is also a change in the $r / r_{0}$ values and the $r / r_{0}$ value for the higher degree of beating is higher than $r / r_{0}$ for the lower degree of beating. The reasons for this change are open to speculation but most probably the increased beating, from 19 to $40 \mathrm{SR}$, closes the bulk structure so that the absorption of water into the sheet is less favoured than a spreading of the drop on the surface of the paper. Despite a closed structure there is still a considerable roughness of the paper and as Oliver et.al (29) discussed a large-scale roughness will result in a higher apparent value of the contact angle. As the beating is increased to much higher degrees, to $70 \mathrm{SR}$, the paper will become smoother and there will no longer be a roughness on the surface which will influence the contact angle reading. It is hence suggested that the contact angle of the most highly beaten pulp is most representative for the contact angle of water on the fibres.

The situation for the spreading of ethylene glycol on the papers is quite different. As can be seen in the figures above this liquid shows a considerable absorption, i.e. large decrease in $\mathrm{V} / \mathrm{V}_{0}$ with time and the contact angle readings with this liquid are not representative of the contact angle between the liquid and the fibres. It will also be difficult, not to say impossible, to use the $r / r_{0}$ to study the spreading kinetics of ethylene glycol on the papers.

When comparing the data in figures $3 \mathrm{a}-\mathrm{c}$ and $4 \mathrm{a}-\mathrm{c}$ it is clear that the change of the contact angle with time is quite different for the different liquids. As discussed above, this might have several explanations depending on whether there is a spreading on or a penetration into the papers. Another factor, as thoroughly discussed by Zosel (16), might be that the spreading/absorption is totally controlled by the properties of the liquids. In order to test this the change of $\operatorname{Cos} \theta$ and $r / r_{0}$ were plotted as a function of time and as a function of a reduced time where the influence of the properties of the liquids has been taken into account. This has been done by multiplying the real time with a factor $\gamma_{1} /\left(\eta_{1} \cdot r_{0}\right)$ (where $\gamma_{1}$ is the surface tension of the liquid, $\eta_{1}$ is the viscosity of the liquid and $r_{0}$ is the radius of the drop before it hits the paper) in order to get a dimensionless time. The results for the most highly beaten homogeneous sheet are shown in figure $7 \mathbf{a}$ and $7 \mathbf{b}$ and $8 \mathbf{a}$ and 8 b below. 


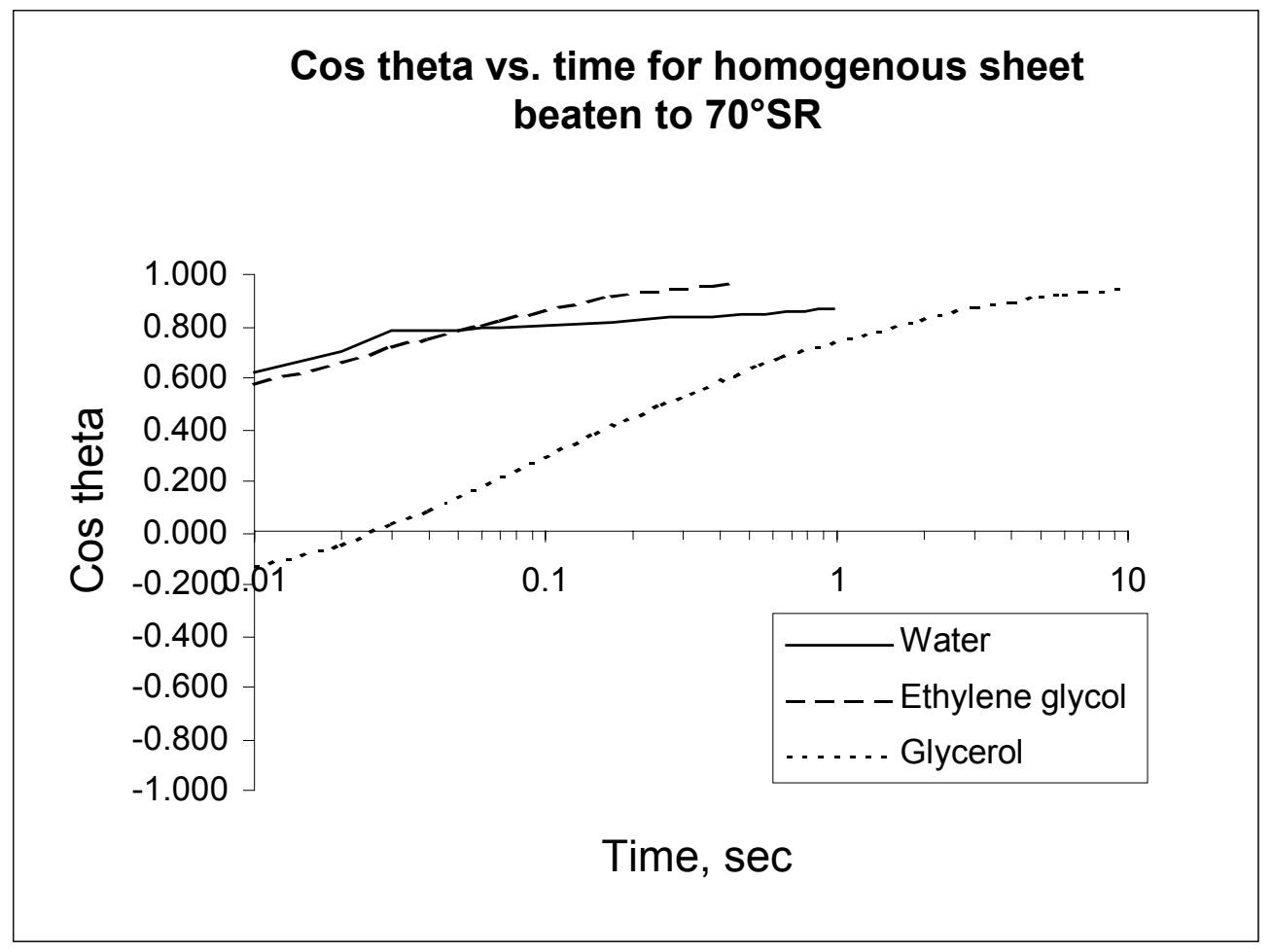

Figure $7 \mathbf{a}$ and $\mathbf{b} . \operatorname{Cos} \theta$ as function of time (a) and reduced time (b).

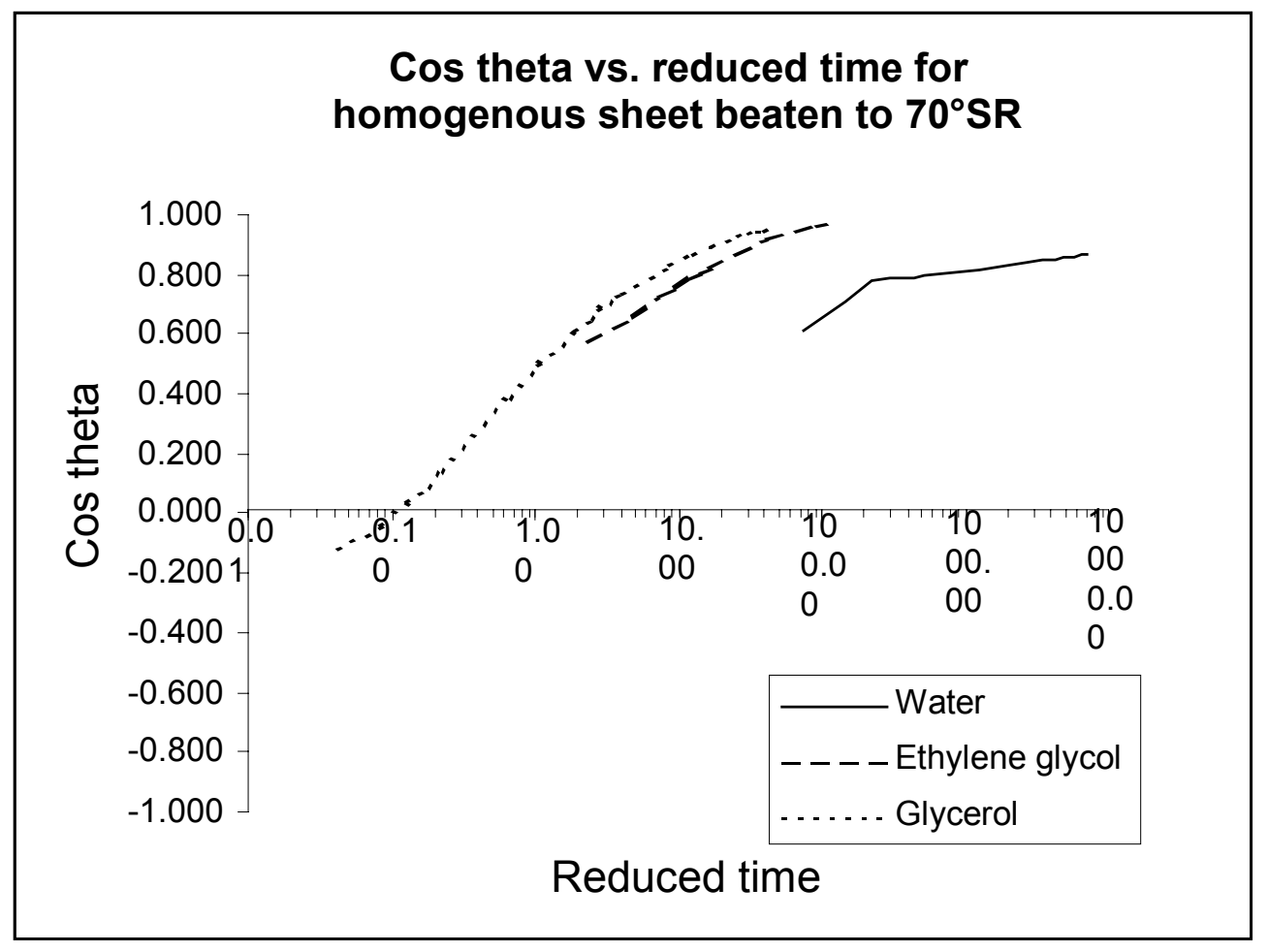

Figure $8 a$ and $b . \quad r / r_{0}$ as a function of time (a) and reduced time (b). 
These figures show that there is a large difference between the liquids when the results are plotted as a function of time but when the results are plotted as a function of reduced time all the results are almost condensed down to a master curve. This indicates that the initial spreading and wetting at short contact times is almost entirely determined by the properties of the liquids. In order to get a correct reading of the contact angle it is hence necessary to allow the $r / r_{0}$ to reach a constant level and then to read the contact angle at that corresponding time. Again it is obvious from figure $8 \mathrm{~b}$ ) that it is only possible to get a reasonable contact angle value for water and glycerol and not for ethylene glycol.

\section{Spreading of liquid drops on papers with different degrees of hydrophobicity and with different types of imprinted structures}

In the previous section it was mentioned that it is difficult to determine a true contact angle or a true surface spreading on paper, especially in a paper made from fibres with a low degree of beating. It was also mentioned that the structure of the paper might be very important for the kinetics of the spreading of different liquids. In order to clarify the importance of the surface energy of the papers and the structure of the paper a series of experiments were conducted where a) the fibres were sized with different amounts of $\mathrm{AKD}$ and $b$ ) the papers were pressed against different wires during drying in order to imprint different patterns on the paper surface. All of these sheets were homogeneous and only fibres with a degree of beating of 40 SR were tested.

Results from the measurements with spreading of water on sheets with different amount of $\mathrm{AKD}$ and different structures are shown in figures 9 a-c.

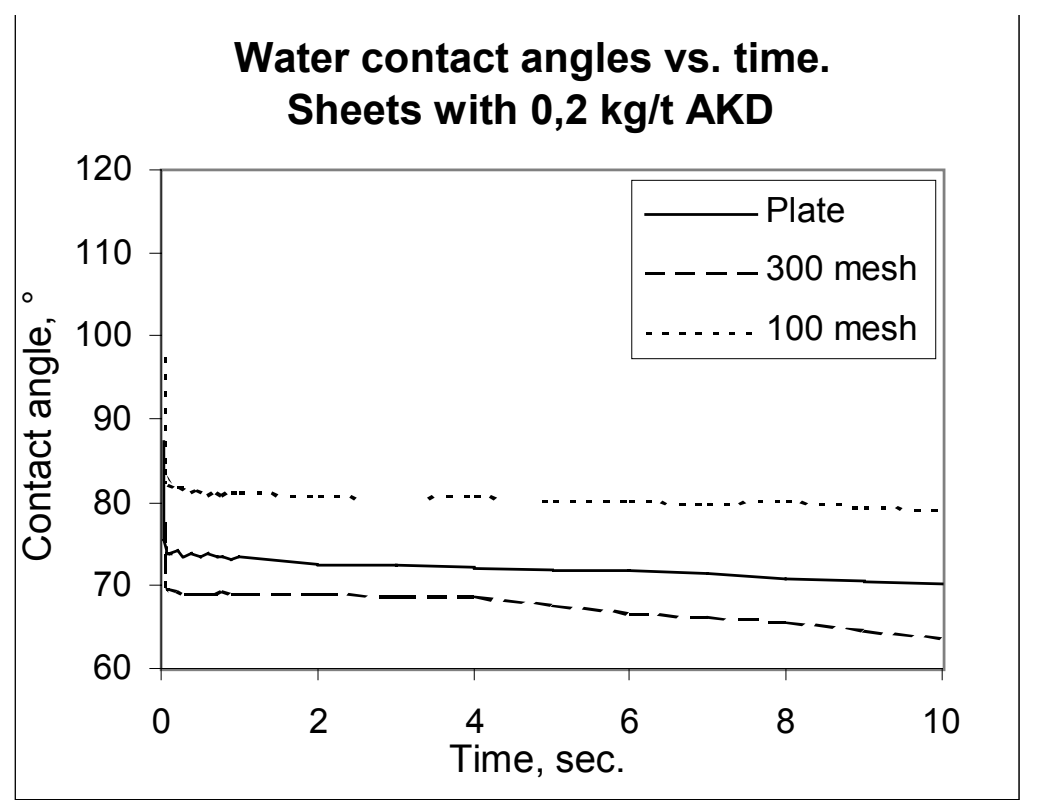

Figure 9a. Change of contact angle with time for water droplets on sheets pressed against different wires during drying. $0.2 \mathrm{mg} / \mathrm{g} A K D$ was added to the paper before sheet preparation and the fibres had a degree of beating of $40 \mathrm{SR}$. 


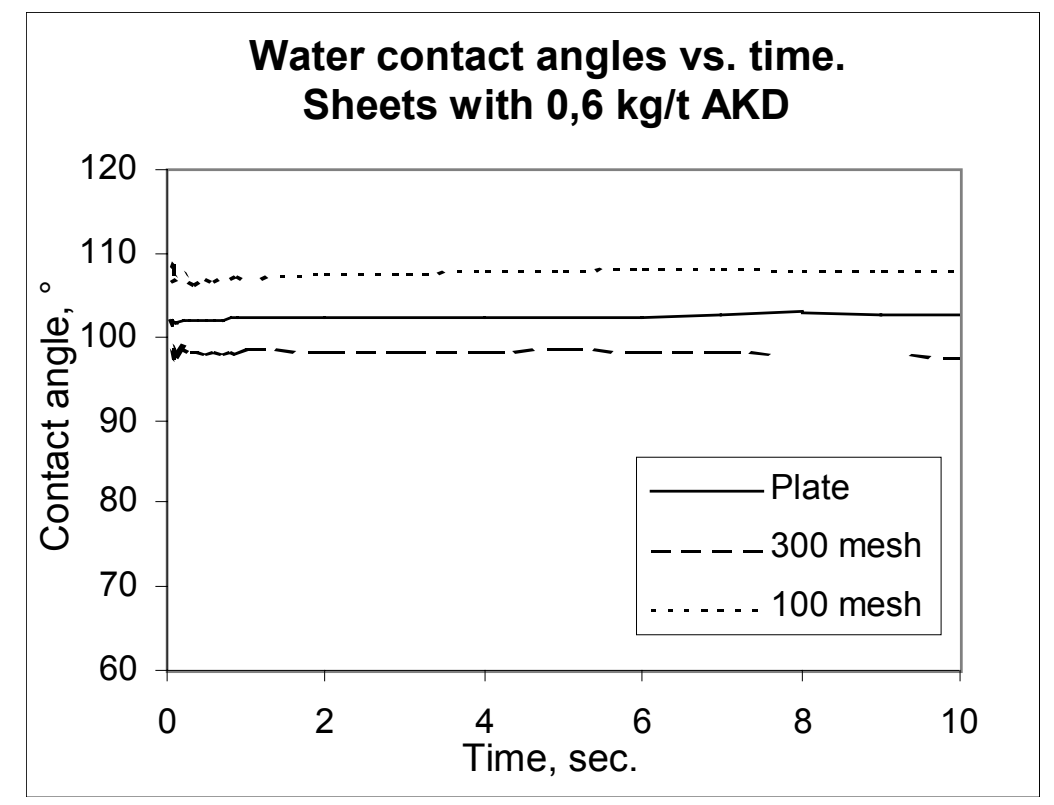

Figure 9b. Change of contact angle with time for water droplets on sheets pressed against different wires during drying. $0.6 \mathrm{mg} / \mathrm{g} A K D$ was added to the paper before sheet preparation and the fibres had a degree of beating of $40 \mathrm{SR}$.

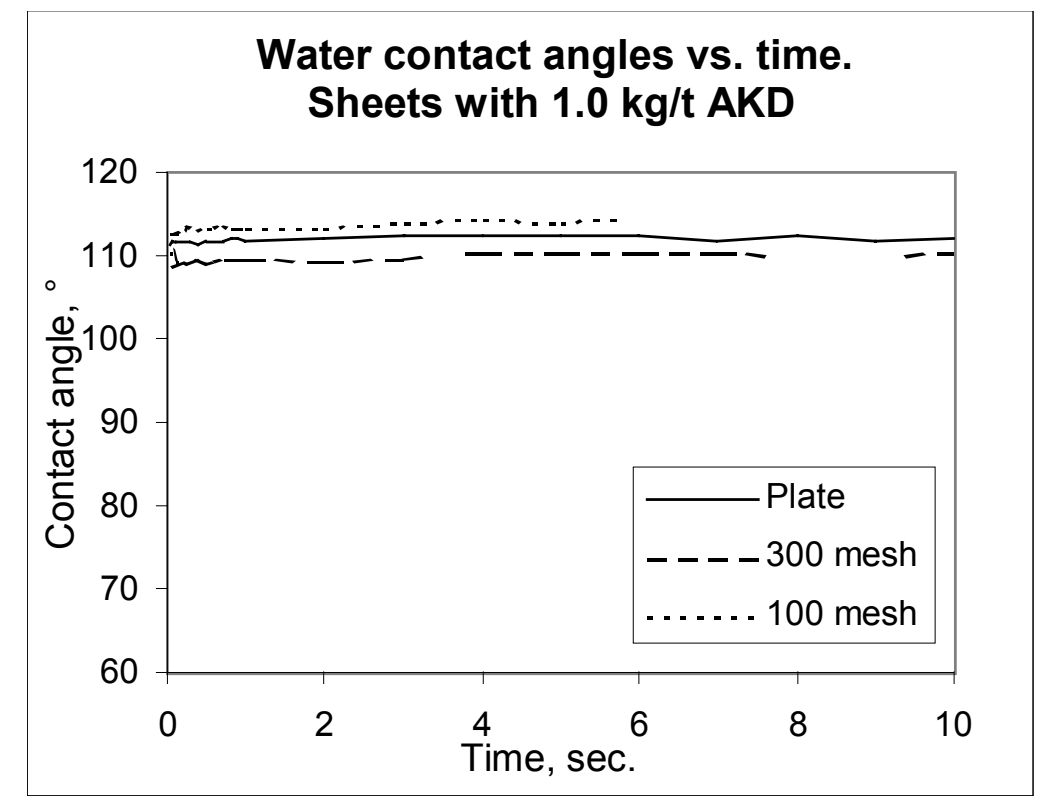

Figure 9c. Change of contact angle with time for water droplets on sheets pressed against different wires during drying. $1.0 \mathrm{mg} / \mathrm{g} A K D$ was added to the paper before sheet preparation and the fibres had a degree of beating of $40 \mathrm{SR}$. 
These figures show that there is a large difference compared with the data for the unsized sheets. In figures 9 a-c there is a much larger contact angle and secondly there is also a much more rapid achievement of a fixed contact angle. This together with the fact that there is no change of the volume of the drop with time strongly indicates that it is safe to determine a contact angle on these kinds of papers. What is also obvious in the figures is the influence of the imprinted surface pattern on the paper. For the paper with the most uneven, i.e. largest amplitude of variations, pattern there is an increase in the contact angle, compared with the paper dried against a plate, and for the paper with the finest pattern the contact angle is lower. This is in close agreement with the results as reported by Oliver et al (14) where it was found that for large scale roughness the contact angle is increased according to the equation introduced by Shuttleworth and Bailey (see for example 14)

$$
\theta_{a}=\theta_{e}+\varnothing_{m}
$$

Where $\theta_{\mathrm{a}}=$ apparent contact angle

$$
\begin{aligned}
& \theta_{\mathrm{e}}=\text { equilibrium contact angle } \\
& \emptyset_{m}=\tanh ^{-1}(|d h / d R|)=\text { Maximum slope of the roughness on the surface }
\end{aligned}
$$

For the small scale roughness it can be suggested that the imprinted pattern forms a continuous network of surface capillaries which actually assists in the spreading of the drops of water according of the Wenzel equation (see for example 14)

$$
\operatorname{Cos} \theta_{a}=\sigma \cdot \operatorname{Cos} \theta_{e}
$$

Where $\sigma=$ Ratio of true to apparent contact area $(>1)$

By examining the surface profiles of the different sheets, which are shown in figure 10, it can be estimated that the $\emptyset_{\mathrm{m}}$ parameter as defined by equation [2] will assume values for the roughest sheets of $5-10^{\circ}$, which is in close agreement with what is shown in figures 9 a-c. By inspection of equation [1] to [3] it is clear that they are most applicable for surfaces with a contact angle lower than $90^{\circ}$ but the concept introduced with the equations are nevertheless very useful. It is naturally also hard to exactly define when there is a changeover from increased spreading to decreased spreading due to the increased roughness but it is interesting to note that both the hydrophobicity and the roughness will influence the spreading of the water drops on the sized sheets. This is also in accordance with recently published results on spreading of water drops on model-surfaces treated with AKD dispersions (30) . 

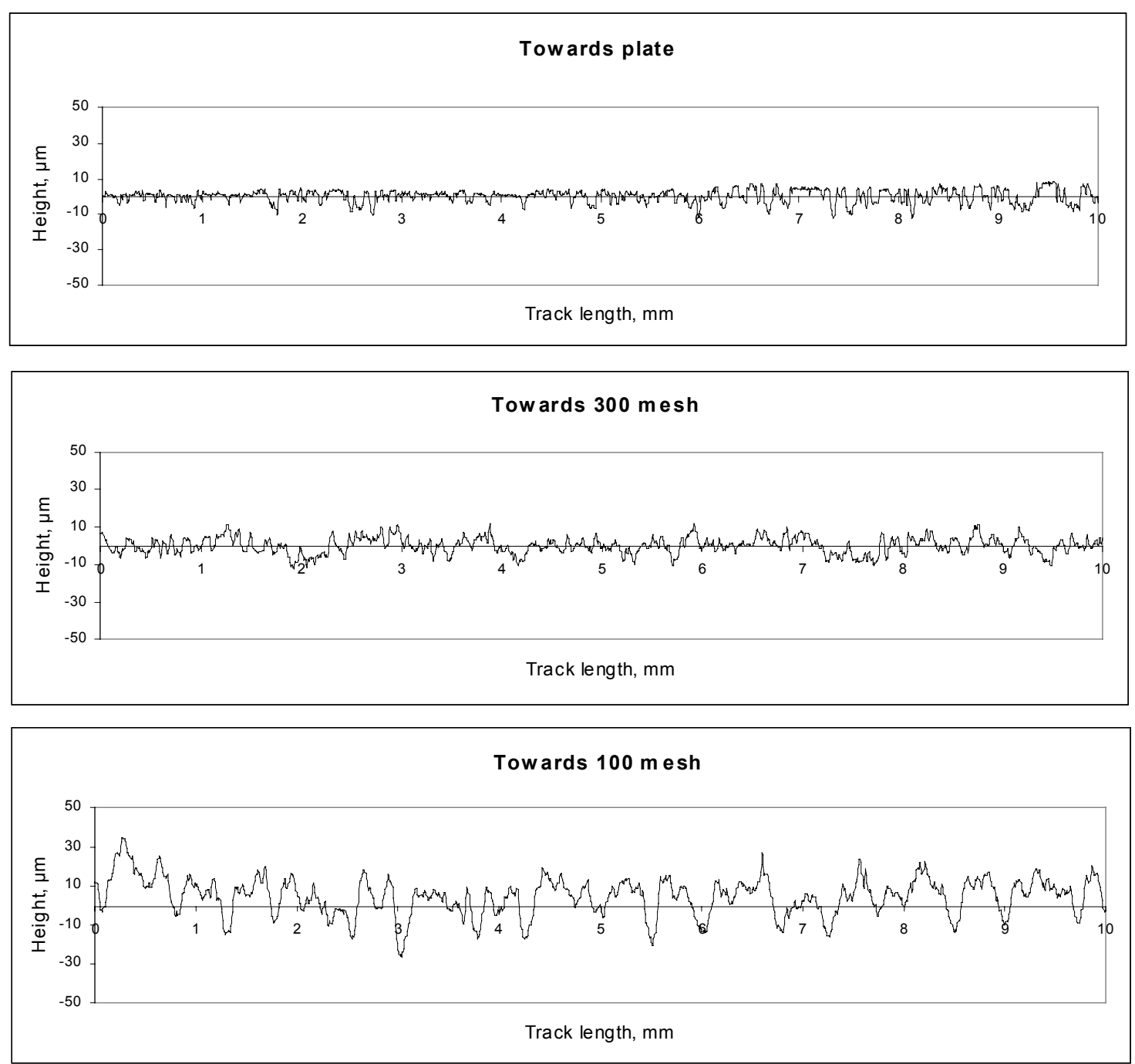

Figure 10. The surface profiles of the papers with different structures as determined with the Optical Profile Tester (OPT). A $\varnothing_{\mathrm{m}}$ parameter was estimated graphically from the slopes in the profile for the sheets pressed against the 100 mesh wire.

It should also be mentioned that studies of spreading of silicone oil droplets on model surfaces with parallel V-shaped grooves (19) showed that the contact angle was increased for spreading perpendicular to the grooves and decreased for spreading parallel to the grooves. This also shows how the dual nature of the roughness on the surface, i.e the balance between connectivity, size and amplitude of the roughness in combination with the hydrophobocity will determine if the spreading is hindered or not. A further rationalisation of the data is hence needed in order to predict the influence of these parameters. This will be discussed below.

Figures 11 a-c show similar data for the spreading of glycerol drops on the different sheets. (It might be added that a similar treatment of the ethylene glycol data was not possible since there was a significant absorption of ethylene glycol also into these sized sheets). 


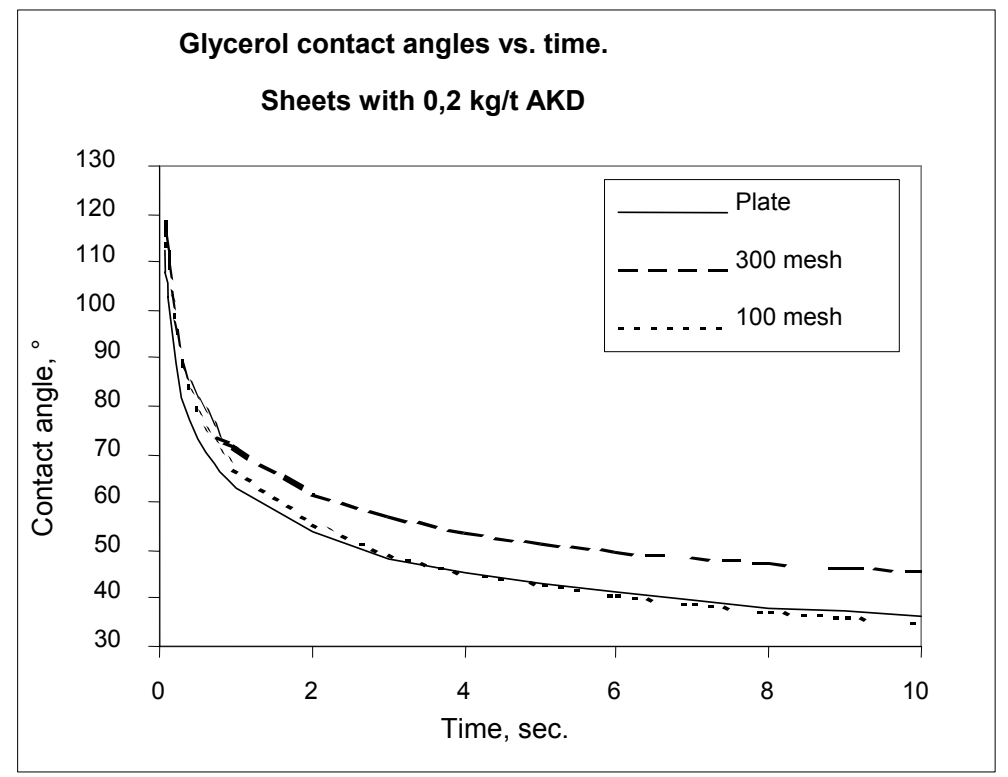

Figure 11a. Change of contact angle with time for glycerol droplets on sheets pressed against different wires during drying. $0.2 \mathrm{mg} / \mathrm{g}$ AKD was added to the paper before sheet preparation and the fibres had a degree of beating of $40 \mathrm{SR}$.

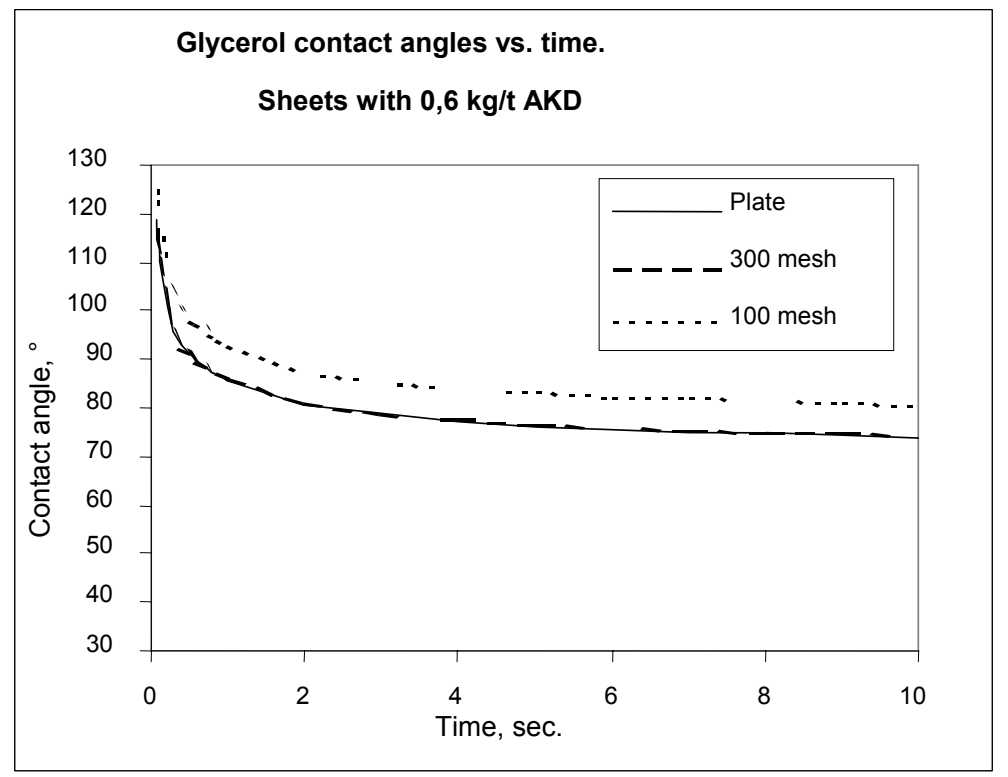

Figure 11b. Change of contact angle with time for glycerol droplets on sheets pressed against different wires during drying. $0.6 \mathrm{mg} / \mathrm{g}$ AKD was added to the paper before sheet preparation and the fibres had a degree of beating of $40 \mathrm{SR}$. 


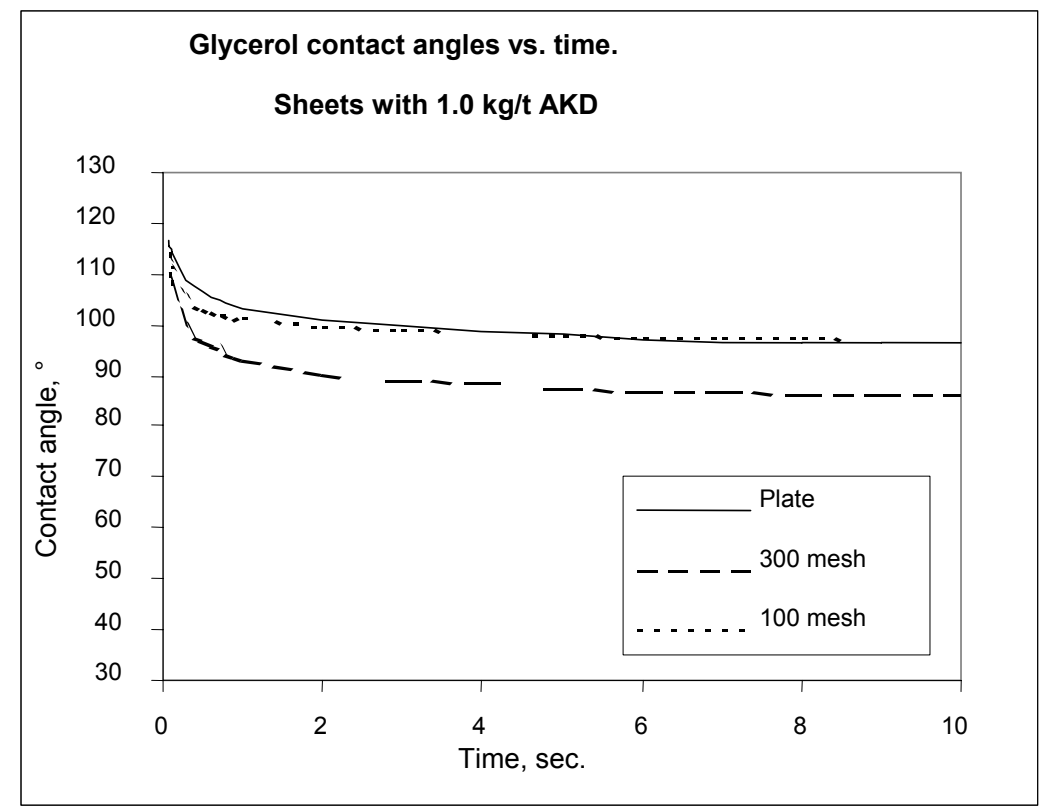

Figure 11c. Change of contact angle with time for glycerol droplets on sheets pressed against different wires during drying. $1.0 \mathrm{mg} / \mathrm{g}$ AKD was added to the paper before sheet preparation and the fibres had a degree of beating of $40 \mathrm{SR}$.

These graphs show that the same clear trend as for water for the different sheets cannot be seen. Generally the sheets pressed against the 100-mesh wire and the plate show the same results whereas the droplet spreading on the sheets pressed against the 300 mesh wire changes from slightly hindered, for the sheets with the lowest degree of sizing, to slightly enhanced for the sheets with the highest degree of sizing. Obviously the spreading parameter $\left(S=\gamma_{\mathrm{s}}-\gamma_{1}-\gamma_{\mathrm{sl}}\right)$ has an influence on the mode of spreading of the droplets on the surfaces. This was also found in (17).

In order to rationalise the data further and in an attempt to compare the results with similar measurements on other rough substrates the approach by Apel-Paz and Marmur (22) was utilised. These authors fit their data to a power law based on an hydrodynamic approach where it is assumed that the drop is spreading on the surface and that a rim of liquid inside the roughness of the grooves is formed. This was also adopted for the data above by plotting the data according to the same power law as that used in (22), i.e.

$$
A / V^{2 / 3}=k(t+\tau)^{n}
$$

$$
\text { Where } \begin{aligned}
\mathrm{A} & =\text { The wetted area } \\
\mathrm{V} & =\text { Drop volume } \\
\mathrm{k} \text { and } \mathrm{n} & =\text { Empirical constants } \\
\mathrm{t} & =\text { Time }(\mathrm{s}) \\
\tau & =\text { Uncertainty in determining time } 0
\end{aligned}
$$


The results from this treatment of the data are shown in figures 12 a-c. As can be seen in these figures it is possible to get a very good match between the experimental data and the power law approach.
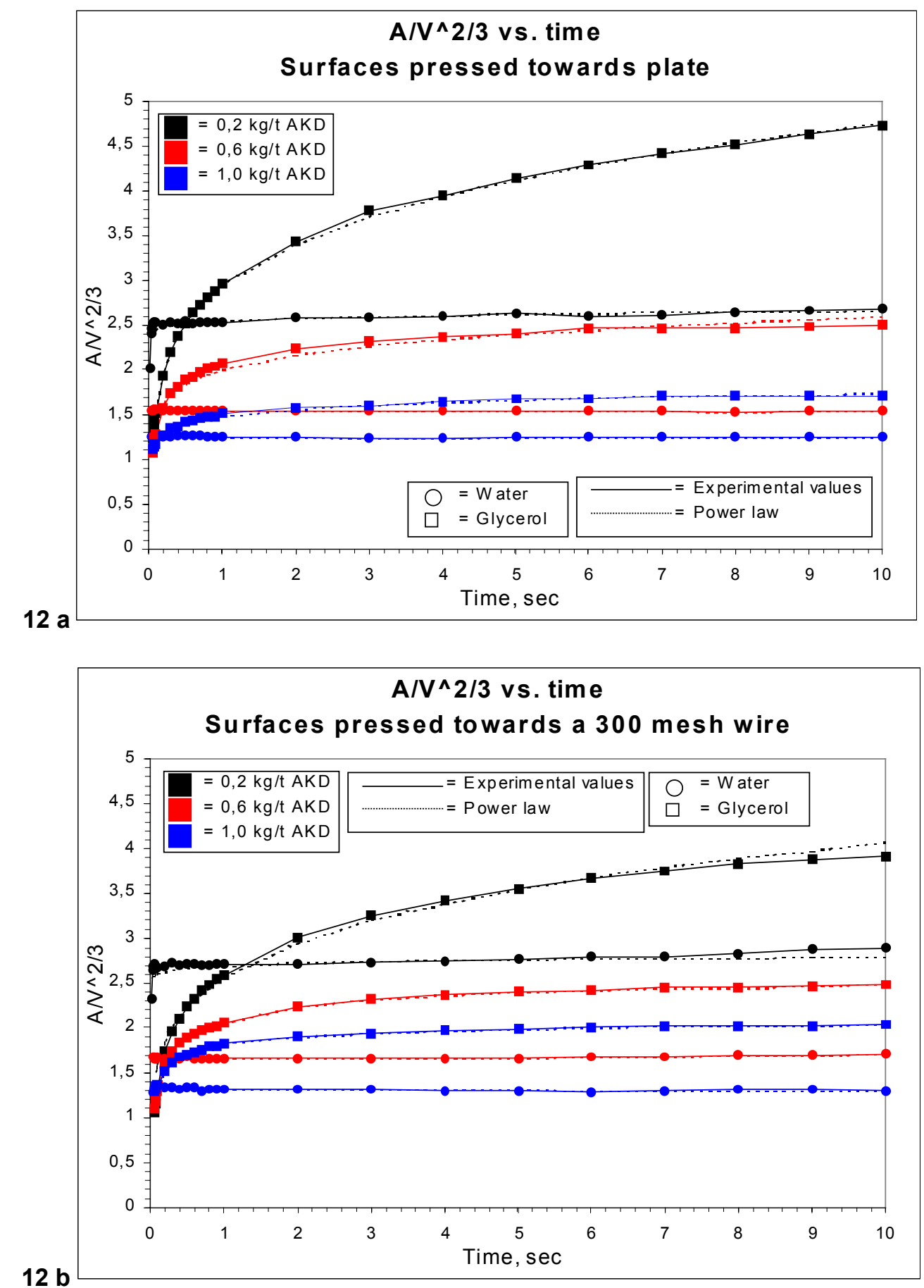
$12 \mathrm{c}$

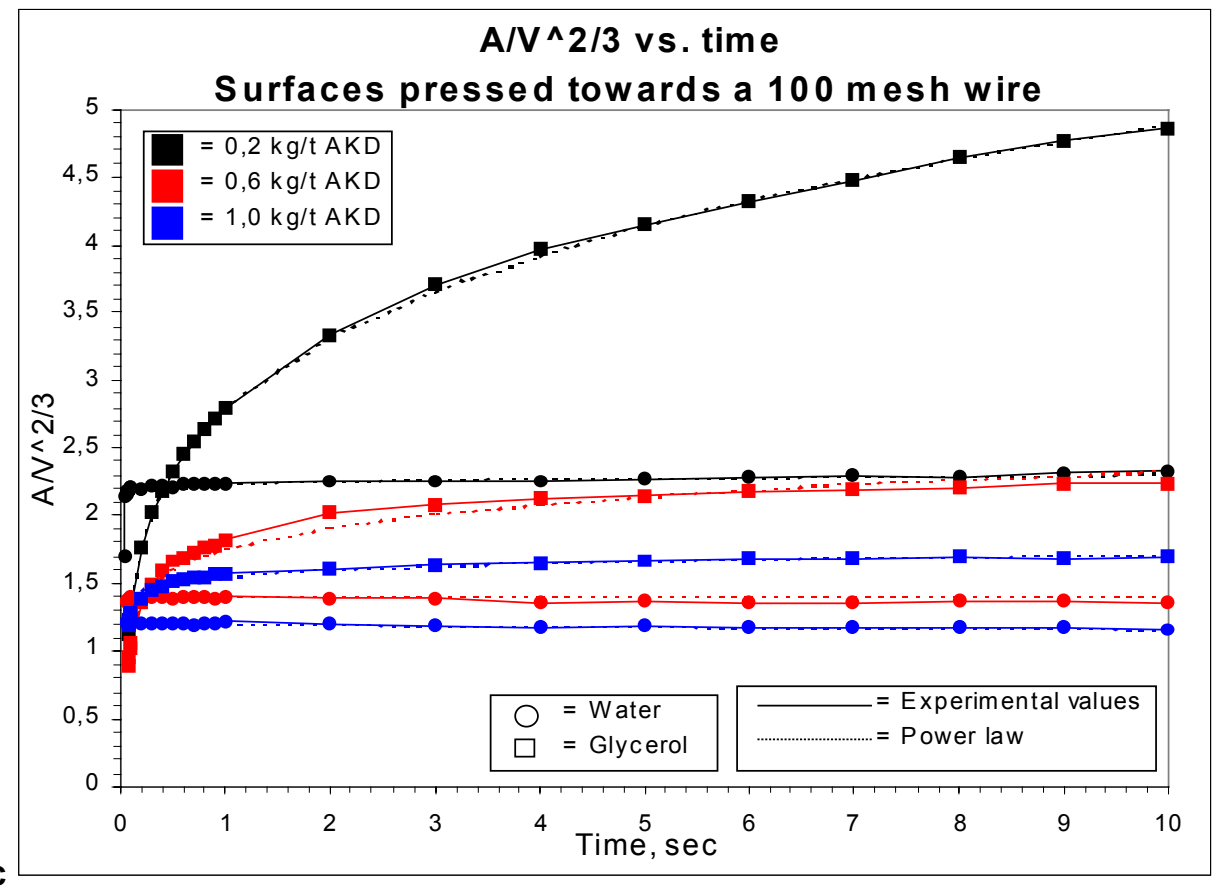

Figure 12 a-c. Kinetics of spreading of water and glycerol droplets on different sheets according to Eq.[4]. Level of AKD addition was 0.2-1.0 mg/g. a = Sheets pressed against $a$ flat plate, $b=$ sheets pressed against 300 mesh wires and $c=$ sheets pressed against 100 mesh wires. All lines in the figures correspond to the power law matching.

The results from these measurements, in terms of $\mathrm{k}$ and $\mathrm{n}$ values are summarised in table 2 below

Table 2. Summary of the empirical constants $k$ and $n$ from the fit of the experimental results to equation [4]. The equilibrium contact angle has also been introduced in order to investigate the influence of the spreading parameter.

\begin{tabular}{|c|l|c|c|c|c|}
\hline $\begin{array}{l}\text { Viscosity } \\
\left(\mathbf{N s} / \mathbf{m}^{\mathbf{2}}\right)\end{array}$ & Sheet type & $\begin{array}{l}\text { Size addition } \\
(\mathbf{m g} / \mathbf{g})\end{array}$ & k-value & n-value & $\begin{array}{l}\text { Cos } \boldsymbol{\theta}_{\mathbf{E}} \\
\text { (Equilibrium })\end{array}$ \\
\hline 0.001 & Plate & 0.2 & 2.55 & 0.018 & 0.33 \\
\hline 0.001 & 100 mesh & 0.2 & 2.23 & 0.015 & 0.17 \\
\hline 0.001 & 300 mesh & 0.2 & 2.70 & 0.015 & 0.36 \\
\hline 1.49 & Plate & 0.2 & 2.98 & 0.20 & 0.81 \\
\hline 1.49 & 100 mesh & 0.2 & 2.82 & 0.24 & 0.81 \\
\hline 1.49 & 300 mesh & 0.2 & 2.57 & 0.20 & 0.69 \\
\hline 0.001 & Plate & 0.6 & 1.54 & 0.000 & -0.22 \\
\hline 0.001 & 100 mesh & 0.6 & 1.40 & 0.001 & -0.13 \\
\hline 0.001 & 300 mesh & 0.6 & 1.66 & 0.001 & -0.29 \\
\hline 1.49 & Plate & 0.6 & 2.02 & 0.110 & 0.27 \\
\hline 1.49 & 100 mesh & 0.6 & 1.77 & 0.120 & 0.16 \\
\hline 1.49 & 300 mesh & 0.6 & 2.07 & 0.090 & 0.27 \\
\hline 0.001 & Plate & 1.0 & 1.25 & -0.0024 & -0.36 \\
\hline 0.001 & 100 mesh & 1.0 & 1.25 & -0.027 & -0.38 \\
\hline 0.001 & 300 mesh & 1.0 & 1.34 & -0.012 & -0.32 \\
\hline 1.49 & Plate & 1.0 & 1.49 & 0.070 & -0.10 \\
\hline 1.49 & 100 mesh & 1.0 & 1.55 & 0.043 & -0.12 \\
\hline 1.49 & 300 mesh & 1.0 & 1.80 & 0.060 & -0.063 \\
\hline
\end{tabular}


As was mentioned earlier it was possible to get a good match with the power law approach but as the sheets become more hydrophobic the $\mathrm{R}^{2}$ values for the water spreading decreases. This can most probably be linked to fact that the water drops reach their equilibrium radius very rapidly and it is hard to get a perfect match at very short contact times. However, as can be seen in figure $12 \mathrm{a}-\mathrm{c}$ the power law fits the data very well also at longer contact times. The good match to the power law can naturally be due by several spreading phenomena but the most obvious reason is that the model as proposed in (22) is correct, i.e the spreading occurs by a rim in front of the drop. This suggestion must however be supported by further investigations and the concept is recommended for future studies.

As shown in the table there is a systematic decrease in $\mathrm{k}$ with a change in the contact angle, as expected, and in order to check if there are any changes in the spreading process the data were plotted as a function of $\operatorname{Cos} \theta_{\mathrm{E}}$ and those results are shown in figure 13 and 14 below.

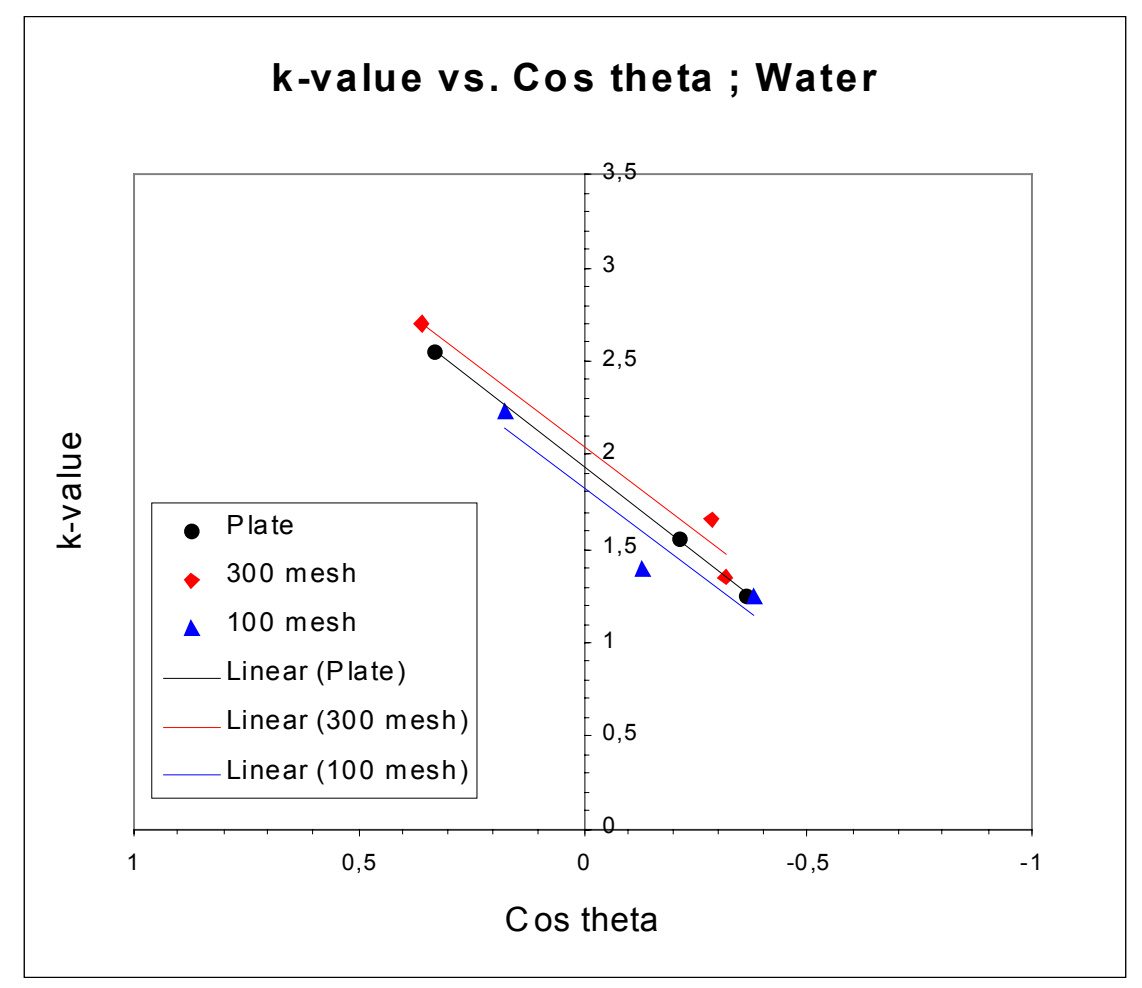

Figure 13. k-values for the spreading of water drops, from the power law fit, as a function of $\operatorname{Cos} \theta_{\mathrm{E}}$ for the different sheets. 


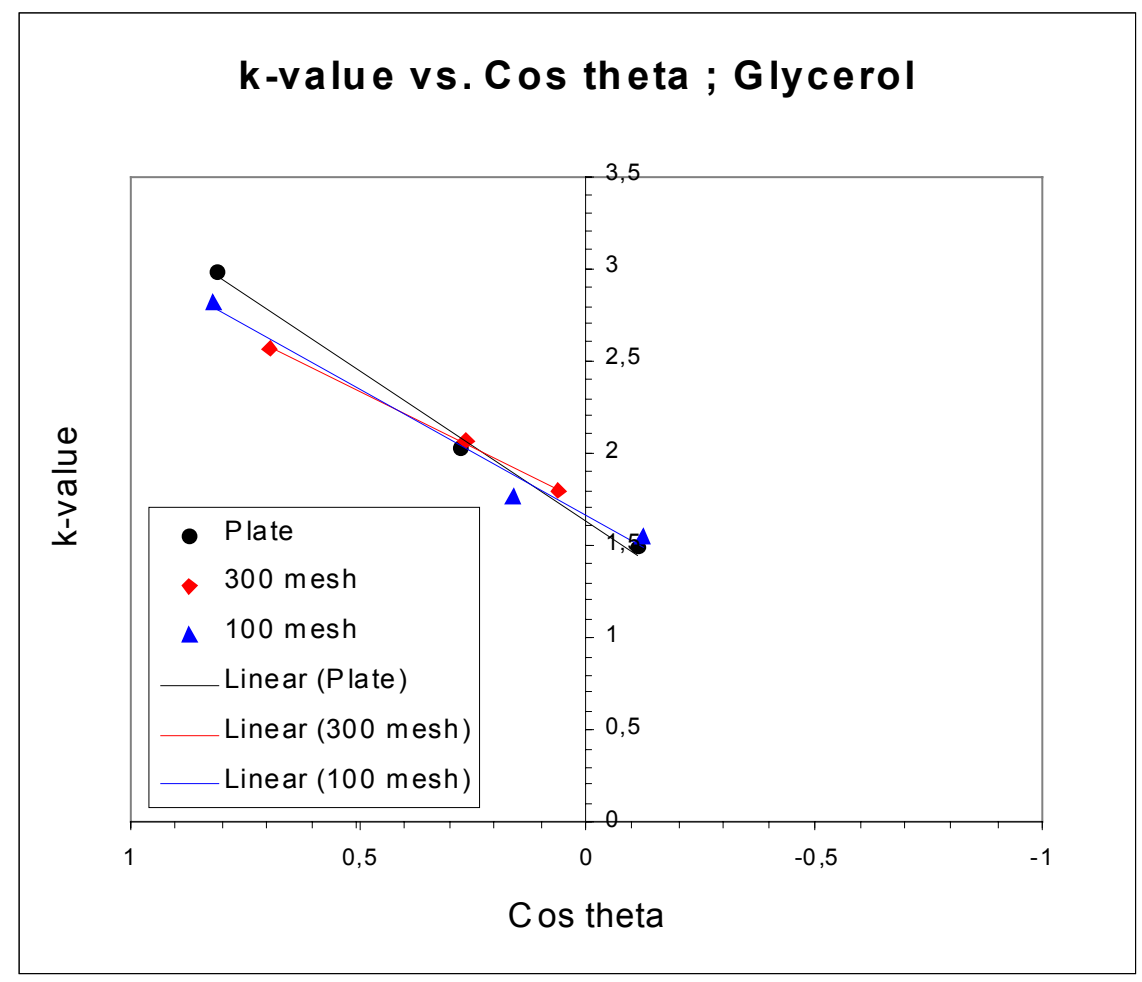

Figure 14. k-values for the spreading of glycerol drops, from the power law fit, as a function of $\operatorname{Cos} \theta_{E}$ for the different sheets.

These figures show that the differences between the different sheets remain the same over the entire $\operatorname{Cos} \theta_{\mathrm{E}}$ range which indicates that the spreading process is the same for the different sheets over this range. As suggested above the spreading of water droplets on these papers is affected in different ways by the different roughness of the sheets. For the glycerol there is an initial, small but clear, difference between the sheets which disappears when the $\operatorname{Cos} \theta_{\mathrm{E}}$ parameter decreases. This indicates, in accordance with the discussion in (17), that the spreading process is changed somewhat and that the glycerol is hindered from entering the capillaries in the surface layer of the sheet as the sheets become more and more hydrophobic. However, the differences are small and the power law approach should be used on other types of sheets to show how useful it can be to predict and explain the spreading of drops of different liquids on paper. 


\section{Summary}

The results in the first part of the investigation shows that

a) It is very difficult to determine a contact angle for papers from normally beaten hardwood fibres. When the degree of beating is increased the droplet spreading on the paper surface dominates over the droplet absorption and a contact angle can be determined once the drop has reached its equilibrium spreading radius, provided the volume of the drop is constant. For the two-ply sheets the top-ply (exposed to the liquid) will dominate the interaction with the liquid.

b) The initial spreading of liquid drops on paper is dominated by the hydrodynamic properties of the liquid and by normalising the data with respect to viscosity and surface tension results in master curves for the different liquids on different sheets.

The second part of the investigation shows that

c) When there is a continuous pattern on the surface, with surfaces capillaries, the contact angle is decreased according to the well-known Wenzel equation compared with the situation with a flat surface. This is the situation for the papers pressed against the fine wire.

d) For the papers pressed against the coarser wire a rougher surface is created with large continuos barriers. These barriers lead to an apparent contact angle between water and paper that is higher than for the flat surface according to the equation proposed by Shuttleworth and Bailey.

e) For glycerol the influence of the surface roughness is not exactly the same except for the sheets with the largest degree of sizing where the fine capillaries on the surface decrease the detected contact angle. This in turn shows an influence of the spreading parameter on the spreading process.

A simple attempt to fit the data to a power law based on the hydrodynamic approach was also conducted. The results from this treatment show that it is possible to get a good match for sheets with virtually only surface spreading and the constants achieved in this treatment can be used to rationalise the spreading data to be compared with other investigations.

In summary this work shows that it is possible to get a good correlation between surface energy, sheet and surface structure and the properties of the liquid in question. However, the correlations are not simple and great care has to be taken to interpret wetting and absorption results correctly 


\section{References}

1. Lyne, B.: "On the interaction of liquids with paper under dynamic conditions",In "Products of Papermaking", C.F. Baker (Ed.) Transactions of the Tenth Fundamental Research Symposium held at Oxford 1993, Pira International, Leatherhead, pp. 885911

2. Aspler, J.: "Interaction of ink and water with the paper surface in printing- A review", Nordic Pulp Paper Res. J.8, 1 (1989) 68-74

3. Kettle, J., Matthews, P., Ridgway, K. and Wågberg, L.: "Investigation of the pore structure of paper by novel porosimetric techniques: application to super- and softnip calanderin", in "'The fundamentals of papermaking materials", Transactions of the $11^{\text {th }}$ Fundamental Research Symposium held at Cambridge 1997, Pira International,Leatherhead,1997, pp.1355-1393

4. Salminen, P.: PhD Thesis, Åbo Akademi, 1988

5. Oliver,J.F., Agbezuge, L. and Woodcock, K.:"Development of a realistic drying model for water-based ink jet inks printed on paper", IS\&T's $7^{\text {th }}$ International Congress on Advancves in Non-Impact Printing Technologies, October 6-11, 1991

6. Oliver, J.F. and Jones, A.Y.: "The inter-relationship between paper structure and print quality in ink jet printing", Mat.Res.Soc.Symp.Proc.197(1990)309

7. Oliver, J.F. and Forsyth,R.C.: “ A dynamic liquid sorption apparatus for studying interactions of microscopic drops in situ on porous substrates, Colloids Surfaces 43(1989)295

8. Wågberg, P. and Wågberg, L.:” Ink-jet printing on uncoated fine papers", 1996 Tappi/CPPA International printing and Graphic Arts Proc. pp. 187-196

9. Wågberg, L. and Annergren, G.: "Physicochemical characterisation of papermaking fibres" in "Fundamentals of Papermaking Raw Materials", C.F. Baker (Ed.), Proceedings of the Conference held at Cambridge 1997,pp.1

10. Marmur, A.: "Equilibrium contact angles: theory and measurement", Colloids Surfaces 116(1996)55-61

11. Brandon, S. and Marmur, A.: "Simulation of contact angle hysterisis on chemically heterogeneous surfaces, J. Colloid Interface Sci.183 (1996) 351-355

12. Marmur, A.: “Contact angles in constrained wetting”, Langmuir 12 (1996) 57045708 
13. Oliver, J.F. and Mason, S.G.: "Liquid spreading on rough metal surfaces", J. Materials Sci. 15(1980) 431

14. Oliver, J.F., Huh, C. And Mason, S.: "An experimental study of some effects of solid surface roughness on wetting", Colloids Surfaces 1(1980) 79-104

15. Marmur, A.: "Equilibrium and spreading of liquids on solid surfaces", Adv. Colloid Interface Sci. 19(1983) 75-102

16. Zosel, A.: "Studies of wetting kinetics of liquid drops on solid surfaces": Colloid Polymer Sci. 271(1993) 680-687

17. Cazabat, A.M. and Cohen Stuart, M.A.: "Dynamics of wetting: Effect of surface roughness", J. Phys. Chem. 90(1986) 5845-5849

18. Cazabat, A.M., Gerdes, S., Valignat, M.P. and Vilette, S.: " Dynamics of wetting: From Theory to experiment", Interface Science 5(1997) 129-139

19. Gerdes, S., Cazabat, A.M.: "The spreading of silicone oil droplets on a surface with parallel V-shaped grooves", Langmuir 13 (1997) 7258-7264

20. Blake, T.D., Clarke, A., De Coninck, J., de Ruijter, M. and Voué, M: ” Droplet spreading: a microscopic approach", Colloids Surfaces 149(1999) 123-130

21. Blake, T.D., Decamps, C., De Coninck, J., de Ruijter, M. and Voué, M: "Thye dynamics of spreading at the microscopic scale", Colloids Surfaces 154 (1999) 5-11

22. Apel-Paz, M. and Marmur, A.: "Spreading of liquids on rough surfaces", Colloids Surfaces 146 (1999) 273-279

23. Tanner, L.H.: "The spreading of silicone oil drops on horizontal surfaces", J.Phys. D: Appl. Phys., 12(1979) 1473-1484

24. Lopez, J. and Miller, C.A.: "Spreading kinetics of liquid drops on solids", J. Collod Interface Sci., 56 (1976) 460-468

25. Blake, T.D.: "Dynamic contact angles and wetting kinetics", in Wettability, J.C. Berg (Ed.), Surfactant Science Series, Marcel Dekker, N.Y., 1993, Vol. 49, pp. 251

26. Wågberg, L. Björklund, M. "On the mechanism behind wet strength development in papers containing wet strength resins". Nordic Pulp \& Paper Research Journal no.119938 p.53-58.

27. Mattsson, L. Wågberg, P. "Assessment of surface finish on bulk scattering materials; a comparison between optical laser stylus and mechanical stylus profilometers". Precision engineering, Vol 15, no 3, 1993, p 141-149. 
28. Marmur, A.: "Radial capillary penetration into paper: Limited and unlimited liquid reservoirs", J. Colloid Interface Sci., 166(1994) 245-250

29. Oliver, J.F., Huh, C.and Mason, S.G.: "An experimental study of some effects of solid surface roughness on wetting", Colloids Surfaces (1980) 79-104

30. Onda, T., Shibuichi, S., Satoh, N. and Tsujii, K.: "Super-Water-Repellent Fractal Surfaces”, Langmuir 12,9(1996) 2125-2127 